\title{
STORMVEX: The Storm Peak Lab Cloud Property Validation Experiment Science and Operations Plan
}

J Mace

Principal Investigator

S Matrosov

B Orr

M Shupe

R Coulter

P Lawson

A Sedlacek

G Hallar

L Avallone

I McCubbin

C Long

$\mathrm{R}$ Marchand

September 2010

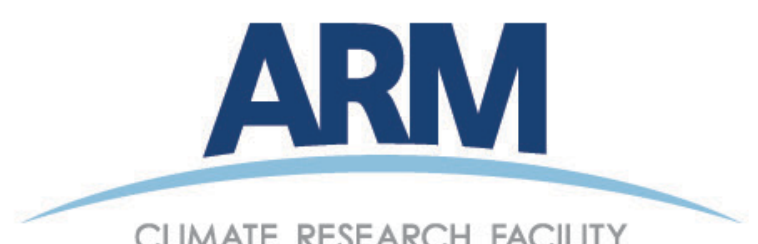




\section{DISCLAIMER}

This report was prepared as an account of work sponsored by the U.S. Government. Neither the United States nor any agency thereof, nor any of their employees, makes any warranty, express or implied, or assumes any legal liability or responsibility for the accuracy, completeness, or usefulness of any information, apparatus, product, or process disclosed, or represents that its use would not infringe privately owned rights. Reference herein to any specific commercial product, process, or service by trade name, trademark, manufacturer, or otherwise, does not necessarily constitute or imply its endorsement, recommendation, or favoring by the U.S. Government or any agency thereof. The views and opinions of authors expressed herein do not necessarily state or reflect those of the U.S. Government or any agency thereof. 


\section{STORMVEX: The Storm Peak Lab Cloud Property Validation Experiment Science and Operations Plan}

September 2010

J Mace, University of Utah

S Matrosov, CIRES, University of Colorado and NOAA/ESRL

M Shupe, CIRES, University of Colorado and NOAA/ESRL

$P$ Lawson, Stratton Park Engineering Corporation

G Hallar, Desert Research Institute

I McCubbin, Desert Research Institute

R Marchand, University of Washington

B Orr, Argonne National Laboratory

R Coulter, Argonne National Laboratory

A Sedlacek, Brookhaven National Laboratory

L Avallone, University of Colorado

C Long, Pacific Northwest National Laboratory

Work supported by the U.S. Department of Energy,

Office of Science, Office of Biological and Environmental Research 


\section{Summary}

During the Storm Peak Lab Cloud Property Validation Experiment (STORMVEX), a substantial correlative data set of remote sensing observations and direct in situ measurements from fixed and airborne platforms will be created in a winter season, mountainous environment. This will be accomplished by combining mountaintop observations at Storm Peak Laboratory and the airborne National Science Foundation-supported Colorado Airborne Multi-Phase Cloud Study campaign with collocated measurements from the second ARM Mobile Facility (AMF2). We describe in this document the operational plans and motivating science for this experiment, which includes deployment of AMF2 to Steamboat Springs, Colorado. The intensive STORMVEX field phase will begin nominally on 1 November 2010 and extend to approximately early April 2011.

The science objectives of STORMVEX include:

Science Objective 1: Collect a large correlative data set of remote sensing observations and direct in situ measurements in liquid, ice, mixed-phase, and precipitating cloud systems for analysis of cloud and precipitation retrievals.

Science Objective 2: Document the properties of aerosols, both natural and anthropogenic, in cloud and precipitation processes in a wintertime, mountainous environment.

Science Objective 3: Document the role of complex terrain on the physical processes that generate clouds and precipitation.

STORMVEX will be based in the town of Steamboat Springs, Colorado, and the adjoining Routt National Forest that is managed by the Steamboat Ski and Resort Corporation. The principal measurement site will be:

1. Storm Peak Lab, where in situ aerosol, cloud, and precipitation properties will be collected.

2. Thunderhead Lodge, where remote sensing elements of AMF2 will be located.

3. Christie Peak, where the AMF2 Aerosol Observing System will be housed.

4. Valley Floor, where guest instruments and additional elements of AMF2 will be located.

In addition, airborne in situ and remote sensing measurements will be provided by the CAMPS campaign that will include the 100 hours of research flight time by the University of Wyoming King Air from roughly early January through February 2011. 


\section{Acronyms and Abbreviations}

AERI

AMF2

AMF2-AOS

AOS

ARM

ARM Climate

Research Facility

BBSS

$\mathrm{BC}$

CAMPS

$\mathrm{CCN}$

$\mathrm{CLH}$

CPC

DMT

DRI

FL

FSSP

IRT

IWC

JPL

Ka-SACR

MFRSR

MMCR

MPL

MWR

NASA

OPS

PARSIVEL

PI

PSAP

RHI

RWP

SPL

SSRC

STORMVEX

SWACR

TSI

USFS

$\mathrm{X}$-SACR
Atmospheric Emitted Radiance Interferometer

ARM Mobile Facility

ARM Mobile Facility Aerosol Observing System

Aerosol Observing System

Atmospheric Radiation Measurement

ARM Facility

balloon-borne sounding system

black carbon

Colorado Airborne Multi-Phase Cloud Study

cloud condensation nuclei

closed-path laser hygrometer

condensation particle counter

Droplet Measurement Technologies, Inc.

Desert Research Institute

flight level

forward scattering spectrometer probe

infrared thermometer

ice water content

Jet Propulsion Laboratory

Ka-Band Scanning ARM Cloud Radar

multifilter rotating shadowband radiometer

millimeter wavelength cloud radar

micropulse lidar

microwave radiometer

National Aeronautic and Space Administration

operations

Particle Size and Velocity (disdrometer)

principal investigator

particle soot absorption photometer

relative humidity with respect to ice

radar wind profiler

Storm Peak Laboratory

Steamboat Ski and Resort Corporation

Storm Peak Lab Cloud Property Validation Experiment

Scanning W-Band ARM Cloud Radar

total sky imager

United States Forest Service

X-Band Scanning ARM Cloud Radar 


\section{Contents}

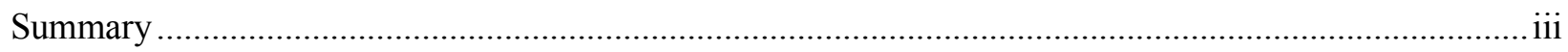

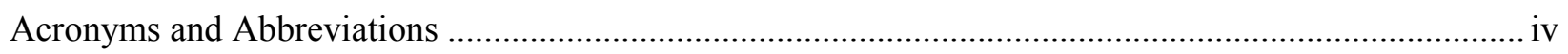

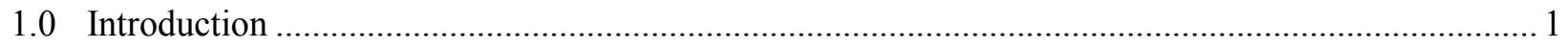

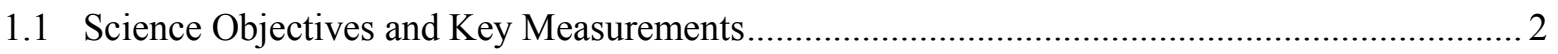

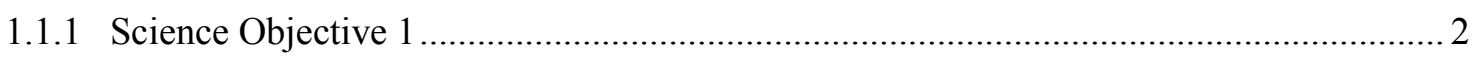

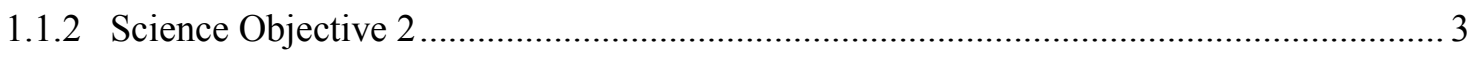

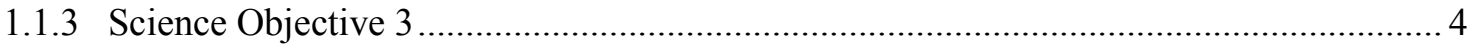

2.0 Physical Locations, Instruments, and Measurements .................................................................. 5

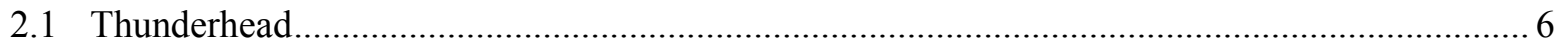

2.1.1 Possible Sitting Adjustments ............................................................................... 9

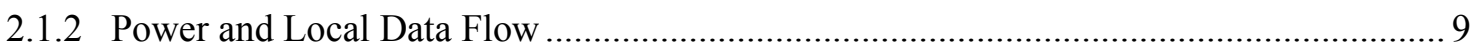

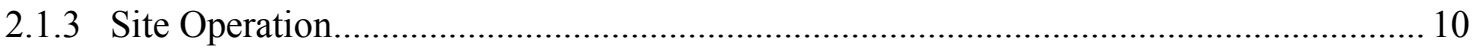

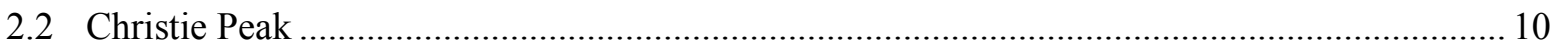

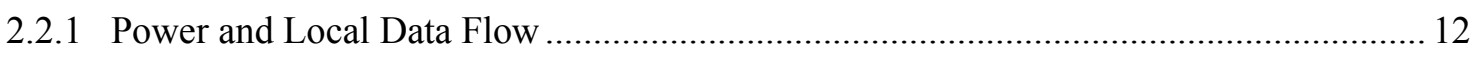

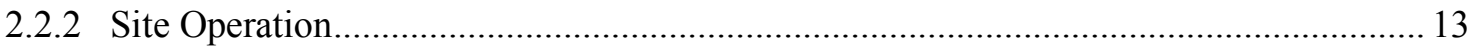

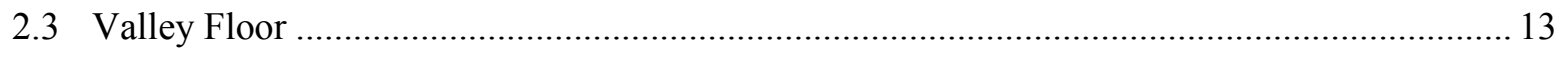

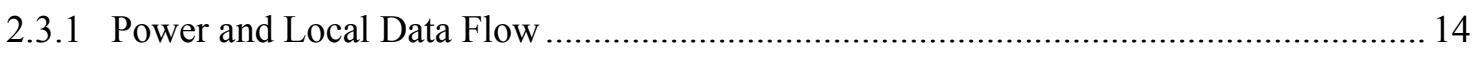

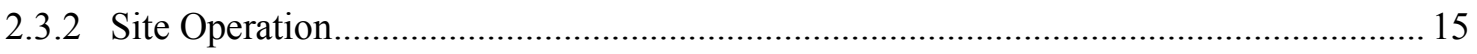

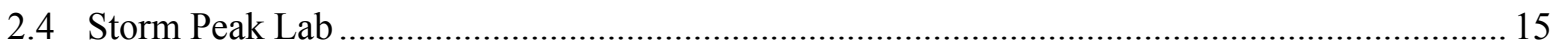

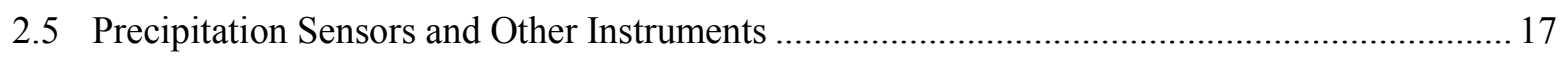

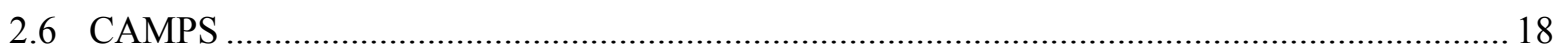

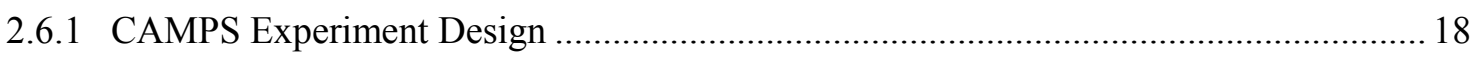

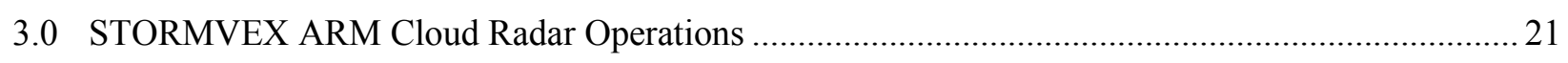

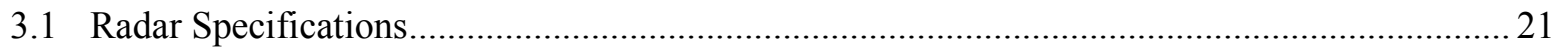

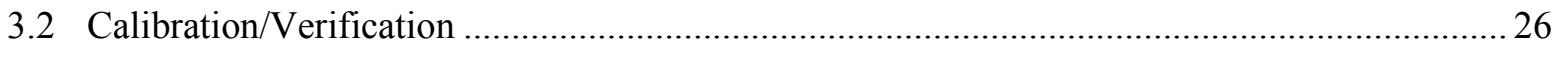

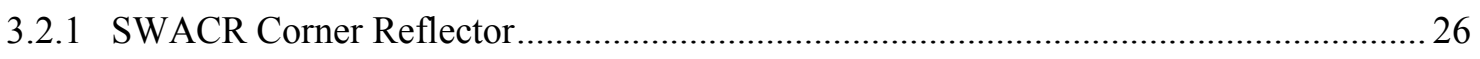

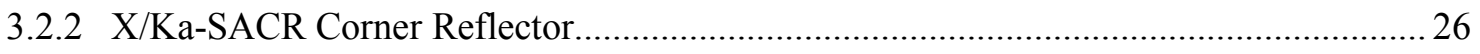

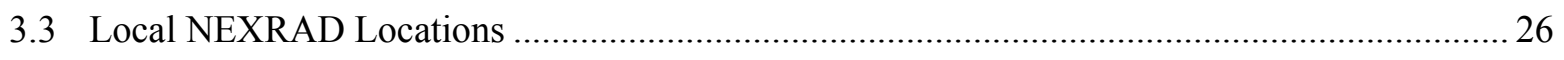

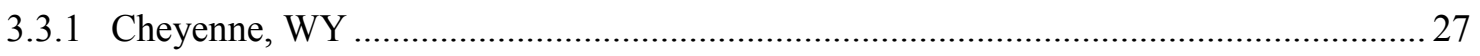

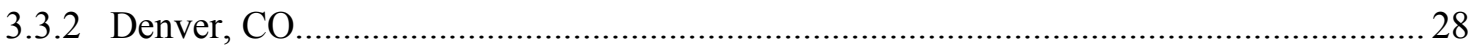

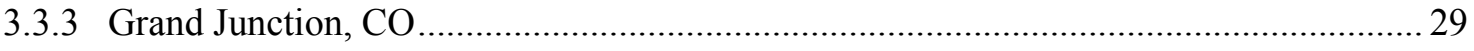

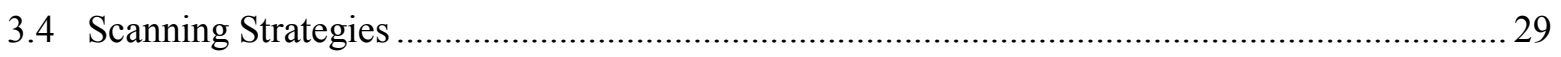

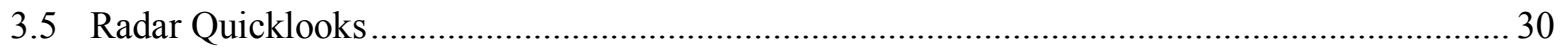

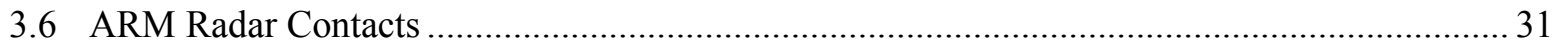

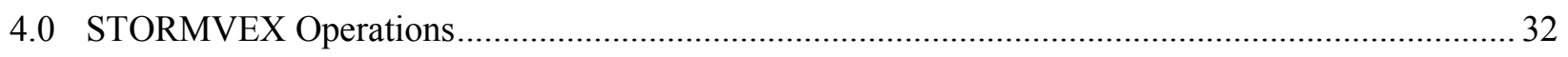

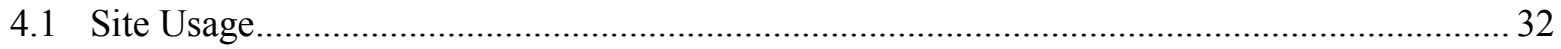




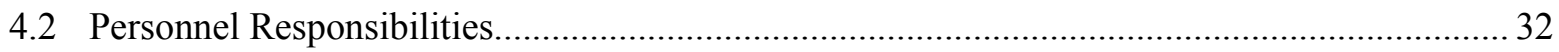

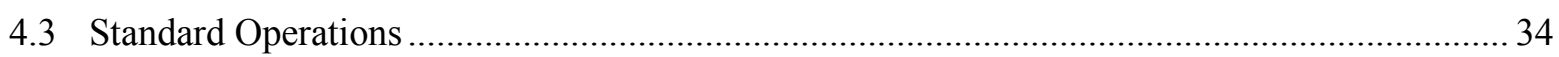

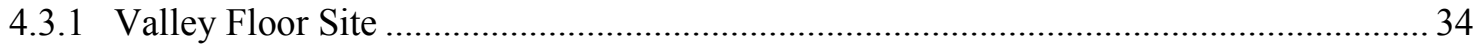

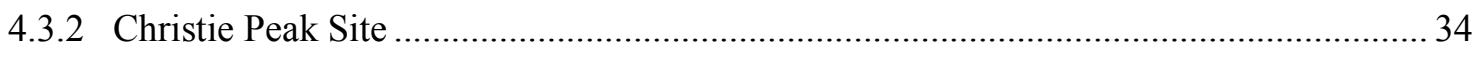

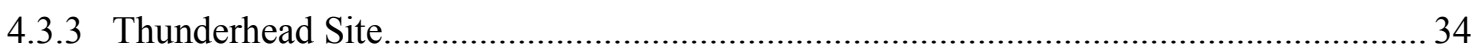

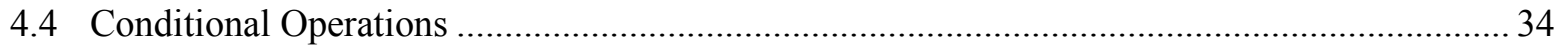

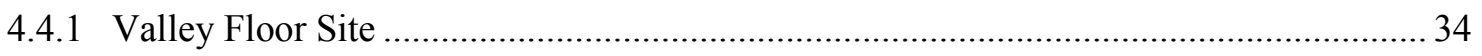

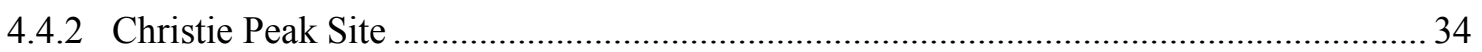

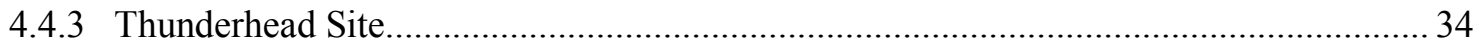

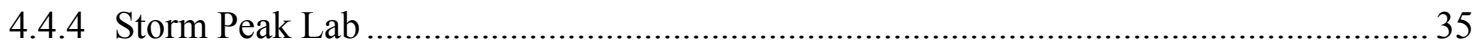

4.5 Communications and Interaction Between STORMVEX and CAMPS ….............................. 35

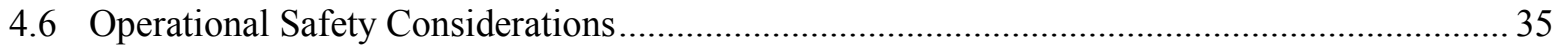

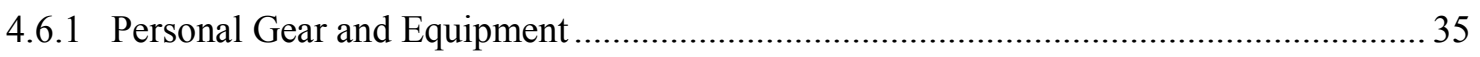

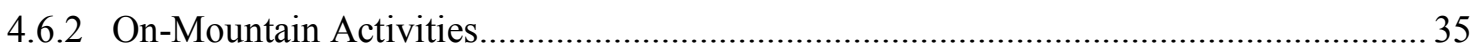

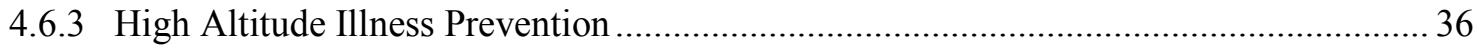

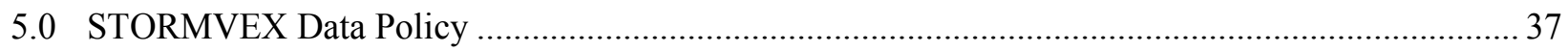

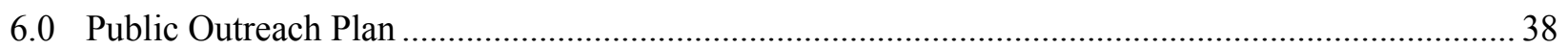

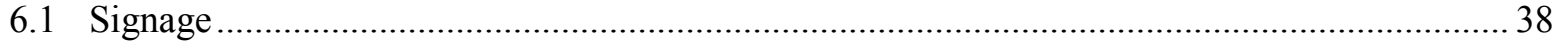

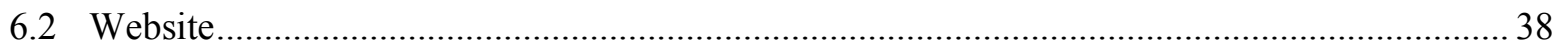

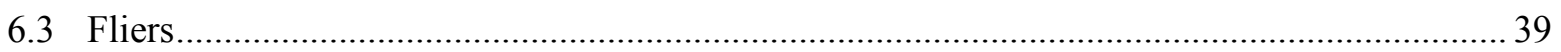

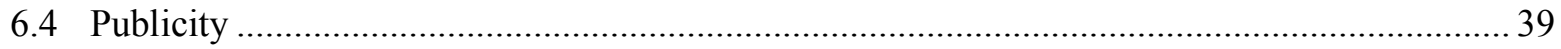

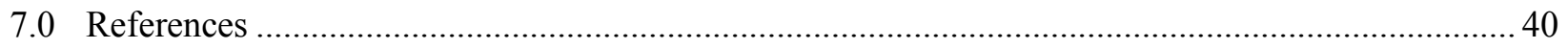

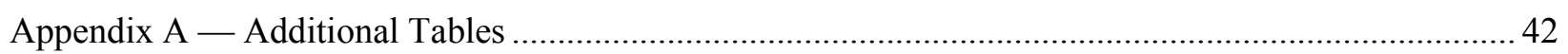




\section{Figures}

1 Overhead satellite view of four major sites during STORMVEX ...........................................1

2 Depiction of the OPS van to be located at the Thunderhead Lodge .........................................7

3 View of Thunderhead and possible locations of SWACR corner reflectorand

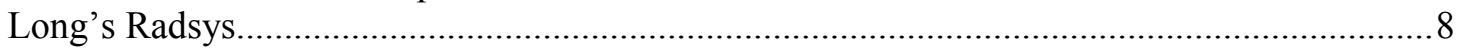

4 Sketch of structure impediments to radiometry field of view from top of OPS van................... 8

5 Sketch of topographical impediment of mountains to east of Thunderhead site .......................

6 View of the AMF2-AOS site at Christie Peak as seen from the Thunderhead gondola ............11

7 On the left is a photograph of ARM AMF1-AOS currently deployed in the Azores, and on the right is a schematic of the aerosol inlet with the five-port sample manifold

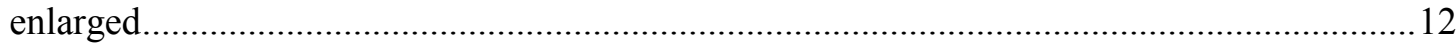

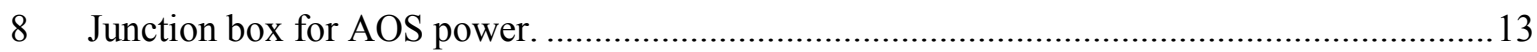

9 Thunderhead Lodge to Storm Peak Lab map and elevation profile........................................22

10 Map and elevation profile from Valley Floor site to SPL................................................25

11 Map and elevation profile between Storm Peak Lab and KCYS radar.................................22

12 Map and elevation profile between KFTG radar and SPL...................................................28

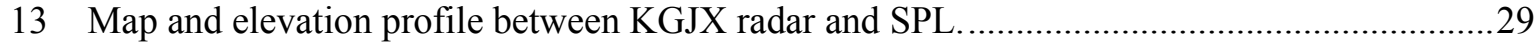

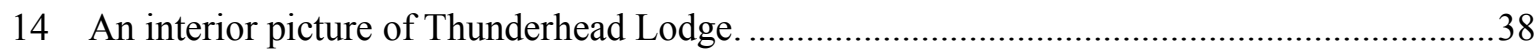

\section{Tables}

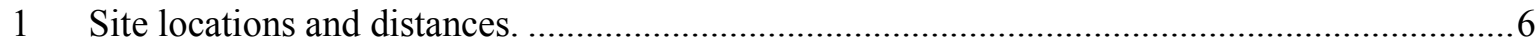

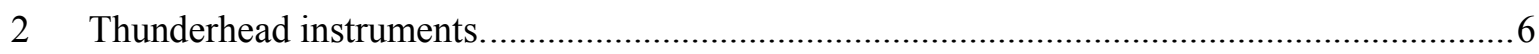

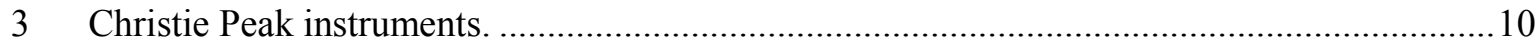

$4 \quad$ Instrumentation at Valley Floor site ............................................................................ 14

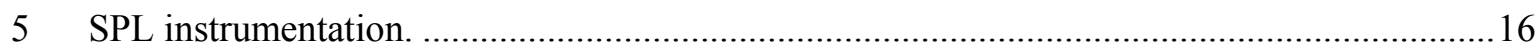

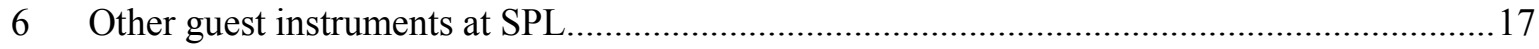

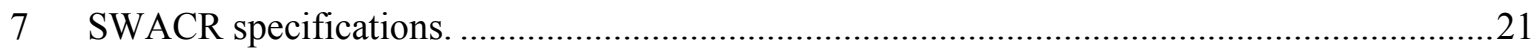

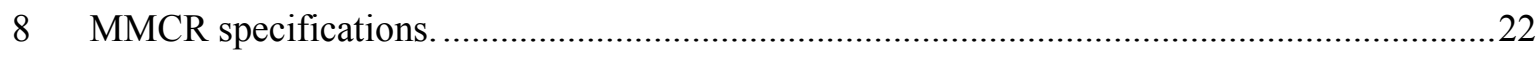

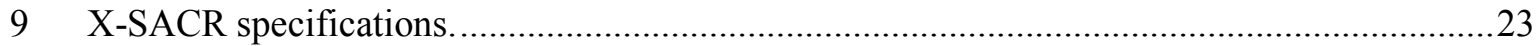

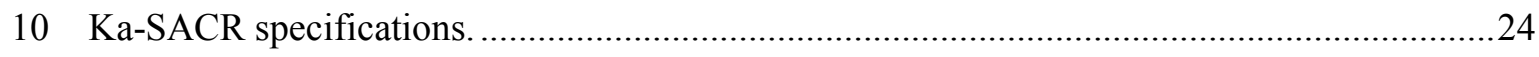

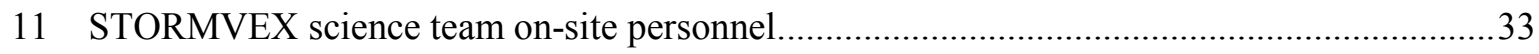




\subsection{Introduction}

The overarching goal of the Atmospheric Radiation Measurement (ARM) Climate Research Facility (ARM Facility) is to improve the representation of physical processes in global models so that the simulation of climate is improved. Quoting from the ARM Science Plan (Ackerman et al. 2004):

"It is critical for ARM to produce a continuous, complete, and rigorous description of the atmospheric physical state in the vertical column above the ARM core instrument facilities. This description must include ... bulk cloud properties such as condensed water contents and mean particle size."

To achieve this goal, ARM is collecting long-term continuous ground-based measurements that describe the physical state of the atmospheric column. Unfortunately, the bulk cloud and precipitation properties that are needed to meet the core ARM Facility objectives are difficult to derive accurately from groundbased remote sensing instrumentation. Because of the importance of these data, the retrieval algorithms used to derive the cloud and precipitation properties continue to be a subject of intense research within ARM (e.g., Frisch et al. 2002, Shupe 2007, Matrosov et al. 2006, Shupe et al. 2005, Matrosov et al. 2003, Mace et al. 2006b, Dong and Mace 2003, Turner 2005). While experiments have been undertaken to provide direct in situ aircraft-based measurements, these measurements are expensive and, at present, the database of independent measurements needed to both validate existing algorithms and to derive new ones is insufficient. The critical need for additional data that can be used to validate in a statistically meaningful fashion cloud and precipitation properties derived from ARM measurements is the primary motivation for the Storm Peak Lab Cloud Property Validation Experiment (STORMVEX). During STORMVEX, a large correlative data set of remote sensing observations and direct in situ measurements in liquid, mixed-phase, and precipitating cloud systems will be created by combining mountain-top observations at Storm Peak Laboratory (SPL) with nearby/collocated measurements from the second ARM Mobile Facility (AMF2). A physical layout of the STORMVEX measurement locations is shown in Figure 1. A more complete description of the instruments and associated measurements is given in Section 2.0.

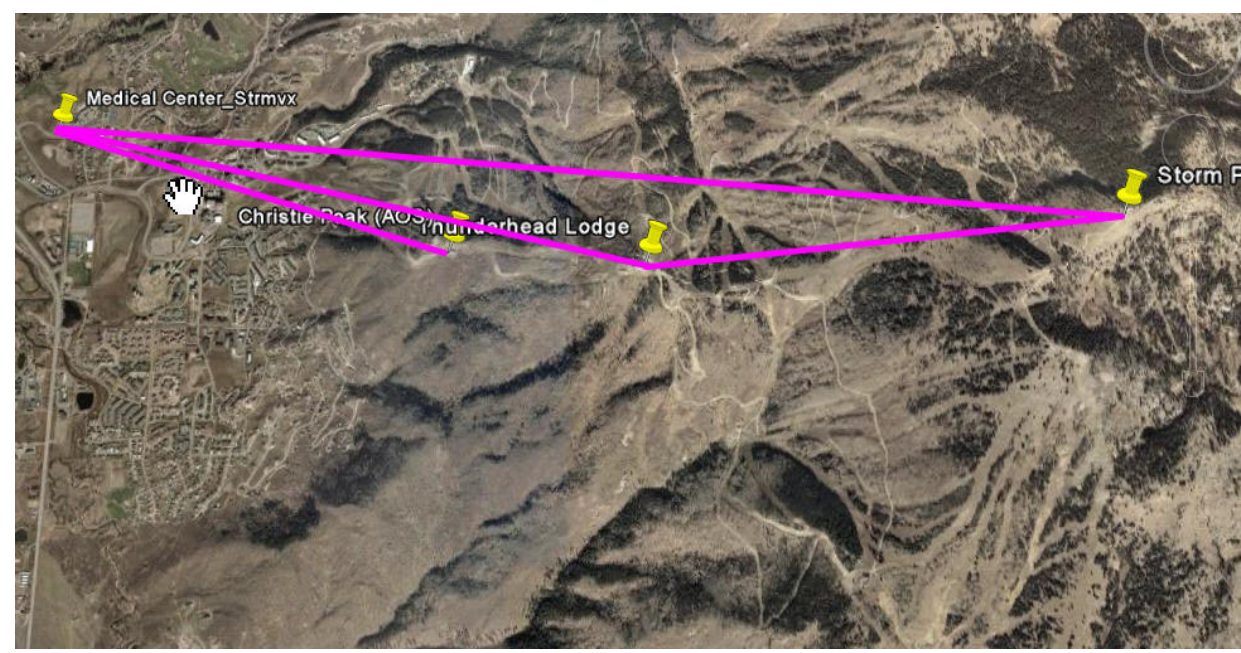

Figure 1. Overhead satellite view of four major sites during STORMVEX. The Medical Center site is at the Yampa Valley Medical Center at the lowest elevation, the mid-mountain site is at the Thunderhead Lodge on the Steamboat Springs Ski Area, the aerosol sampling site is at Christie Peak, and the mountain top site is located at Storm Peak Lab. 
In addition, STORMVEX will provide a data set that can be used to help characterize the role of aerosols, both natural and anthropogenic, in cloud and precipitation processes. Measurements of the aerosol size spectrum and optical properties, along with concentrations of cloud condensation nuclei and trace gases, will be obtained.

The data set will also enable investigation of the effects of complex terrain on the physical processes that generate clouds and precipitation. During STORMVEX, the AMF2 cloud radar and microwave radiometers will be scanned to characterize spatial variability. It has been a long-standing goal of ARM to produce a cloud and radiation data set in a mountainous region (DOE 1990), and STORMVEX data will help meet this object.

This document describes planned experiment operations and observational resources that will be deployed during STORMVEX. In addition to ARM instrumentation, the STORMVEX deployment will benefit significantly from Desert Research Institute (DRI) instruments at SPL, support from the National Science Foundation in funding deployment of the Wyoming King Air and participation by investigators from National Aeronautic and Space Administration (NASA) and several universities under a wide array of external funding. Given the diversity of instrumentation operating in a potentially harsh winter environment, it is critical that the role of all instrumentation and each participant is understood, and that is the objective of this document.

\subsection{Science Objectives and Key Measurements}

In this section, we discuss STORMVEX science objectives and highlight key measurements needed to meet these objectives. A description of measurement sites, instruments, and measurements is given in Section 2.0 of this document.

\subsubsection{Science Objective 1}

- Collect a large correlative data set of remote sensing observations and direct in situ measurements in liquid, ice, mixed-phase, and precipitating cloud systems for analysis of cloud and precipitation retrievals.

In order to meet this objective, a complete set of ARM ground-based remote sensing observations (at least those that are used in cloud and precipitation microphysical retrievals) needs to be obtained. Of key importance will be cloud radar (calibrated radar-reflectivity, both copolar and crosspolar, and Dopplervelocity), polarized micropulse lidar (polarized backscatter), microwave radiometer (microwave brightness temperatures), Atmospheric Emitted Radiance Interferometer (AERI) (spectrally resolved atmosphere infrared emissions), multifilter rotating shadowband radiometer (MFRSR) (direct normal, diffuse, and total horizontal solar irradiance at $415 \mathrm{~nm}, 500 \mathrm{~nm}, 615 \mathrm{~nm}, 673 \mathrm{~nm}, 870 \mathrm{~nm}$, and $940 \mathrm{~nm}$ ) and downwelling broadband shortwave and longwave.

Of equal importance will be in situ measurements of the full cloud and precipitation drop size distribution (e.g., from 2D-S, high volume precipitation sensor, and forward scatter precipitation probes (FSSP) with independent measurements of total liquid water and total ice content (e.g., Nevzorov probe) and precipitation amount. Because of the significant sensitivity of retrieval algorithms to ice crystal habit, observations with a cloud particle imager are also critical. 
Ideally, all of the remote sensing observations would be perfectly collocated with the in situ measurements. Because the in situ measurements are located on a mountaintop (SPL observation deck) and many of the remote-sensing data are limited to nadir pointing (e.g., AERI, radar Doppler-velocities away from nadir provide little information on particle fall velocities), this is not possible. The strategy is therefore to place the remote sensors in close proximity to the in situ site (i.e., Thunderhead Lodge, which is $2.4 \mathrm{~km}$ distant). Most of the sensors will primarily operate in their typical "vertically pointing mode;" however, the cloud radar will be used to scan from nadir to just above SPL. (A complete description of the radar scanning strategy is given in Section 3.0.) We will therefore be able to use the observed radar reflectivity to gauge potential changes in cloud microphysics over this small distance. If changes in the distributions of radar reflectivity are observed between SPL and Thunderhead site, statistical evaluations of the remote sensing retrievals properties will be undertaken as a function of the observed reflectivity. In effect, assuming that the statistical relationships between reflectivity and microphysics at SPL applies to the data collected in the vertical column above the Thunderhead Lodge, we can infer the microphysical properties of the clouds and precipitation. We anticipate this analysis will also be aided by additional aircraft in situ sampling from Wyoming King Air under external support from the National Science Foundation.

Observations of polarized reflectivity with cloud radar scan-angle will also be used to evaluate ice-crystal habit retrievals. If successful, this technique may prove to be a very useful addition to a variety of microphysical retrieval approaches that are sensitive to crystal habit but, at present, we must treat this as an unknown parameter.

\subsubsection{Science Objective 2}

- Characterize the role of aerosols, both natural and anthropogenic, in cloud and precipitation processes.

Measurements of the aerosol size spectrum and concentrations of cloud condensation nuclei will also be undertaken at SPL and Christie Peak sites. The spatial orientation of these two sites will provide an opportunity to study the processing of atmospheric aerosols by clouds by contrasting the measurements at these sites, as Christie Peak is usually below cloud while SPL is in cloud. A three-wavelength nephelometer and particle soot absorption photometer (PSAP) at Christie Peak will characterize aerosol optical properties, as will MFRSRs deployed at all four sites.

A minimum of twice daily radiosonde launches (8:00 am and 3:00 pm local time) from the valley floor, along with radar wind profiler and local surface meteorological observations at several points on the mountain, will help characterize (diurnal) variations in the boundary layer.

At SPL instruments will be deployed to determine the number density and chemical composition of cloud condensation nuclei and ice nuclei. This will be accomplished by deploying a cloud condensation nuclei (CCN) Counter and Ice Nuclei (IN) chamber, each followed by a counterflow virtual impactor to separate drops and ice crystals, respectively. The nuclei will then be analyzed with mass spectrometry (single particle and Aerodyne aerosol mass spectrometers). Ancillary measurements will include aerosol number and size distribution, nephelometer, and PSAP. During cloudy periods, droplets and ice crystals will be separated from clouds using a counterflow virtual impactor inlet. Alternately, interstitial and background aerosol will be analyzed with the mass spectrometers during all periods. 
One area of particular interest is the correlation between black carbon age and precipitation wash out. Specifically, since fresh soot is known to be hydrophobic and aged soot hydrophilic, it is reasonable to expect that aged black carbon would more readily activate, thereby providing a mechanism for efficient precipitation wash out. In contrast, should little processing occur, little loss of black carbon might take place allowing the semi-direct effect to influence cloud lifetime.

\subsubsection{Science Objective 3}

- Investigate of the effects of complex terrain on the physical processes that generate clouds and precipitation.

As mentioned in connection with Science Objective 1, the ARM cloud radar will be scanned to provide some insight into the horizontal variability of cloud and precipitation in the area. This scanning will include a mixture of reflectivity-height scans and azimuthal scans (see Section 3.0), which will also provide information on wind velocity. The microwave radiometer will also be scanned, including during cloudy conditions. These data will likewise be useful in characterizing the amount of variability in the area. Precipitation, in particular, is expected to vary significantly on small spatial scales, and additional instruments precipitation gauges will provide some characterization in the experiment area to help examine correlation of reflectivity with precipitation amount (snow fall).

A major component of STORMVEX will be contributed by Colorado Airborne Multi-Phase Cloud Study (CAMPS) program that includes the University of Wyoming King Air research aircraft. The Wyoming King Air, instrumented with both remote (cloud radar and cloud lidar) and in situ sensors (cloud and particle probes, total water hygrometer), will gather data about the vertical and horizontal structure of cold mixed-phase clouds. Macrophysical and microphysical parameters will be analyzed with respect to cloud formation mechanism and local topography to assess the role of variable vertical forcing. This project is timed to function in concert with STORMVEX. The measurements gathered during CAMPS flights will provide in situ data in the upper regions of clouds and will help to assess the horizontal and vertical inhomogeneities of cloud properties. These measurements will contribute substantially to all aspects of STORMVEX by documenting the role of local topography to the variation of cloud and precipitation. 


\subsection{Physical Locations, Instruments, and Measurements}

STORMVEX will be based in the town of Steamboat Springs, Colorado. Instrument will be deployed at four primary sites. As depicted in Figure 1, these sites are:

1. Storm Peak Lab

The DRI's Storm Peak Laboratory (3210 m above mean sea level) is located on the west summit of Mt. Werner in the Park Range near Steamboat Springs in northwestern Colorado. This site has a long history in cloud and aerosol studies (Hindman et al. 1994; Borys and Wetzel, 1997).

The Storm Peak facility includes an office-type laboratory module for computer and instrumentation set up with outside air ports and cable access to the roof deck, a cold room for precipitation and cloud rime ice sample handling, a $150 \mathrm{~m}^{2}$ roof deck area for outside sampling equipment, a full kitchen and overnight living accommodations. The laboratory has been equipped recently with a state-of-the art broadband high-speed internet connection with a wireless network for visiting computers.

2. Thunderhead Lodge

The Thunderhead Lodge site is located approximately $2.4 \mathrm{~km}$ west of SPL at an elevation of approximately $2760 \mathrm{~m}(\sim 440 \mathrm{~m}$ below SPL). This site is easily accessible by road and by gondola during ski-resort operations. The site has a clear line of site to the SPL and valley floor sites.

A variety of AMF2 instrumentation will be deployed at this location (as listed in Table 2) including the scanning W-band radar, polarization micropulse lidar (MPL), passive microwave radiometer (MWR), and AERI. These instruments will be housed in two containers. A radar calibration target will be placed nearby at the top of the Burgess Creek Lift (460 m distant). Hemispherical broadband radiation measurements may also be set up at near the Burgess Creek lift to avoid influence for the nearby Lodge building.

\section{Christie Peak}

The aerosol measurement component of AMF2 known as the AOS (Aerosol Observing System) will be deployed on Christie Peak. Christie Peak is located between the Thunderhead gondola and the Christie Peak Express lifts. Proximity to the Christie Peak Express ski lift provides ready access to the AOS container. This site overlooks the Valley Floor site. This site is strategically located to examine the diurnal evolution of the local aerosol optical and microphysical properties as they evolve in the boundary layer during the day.

\section{Valley Floor (Near Medical Center)}

A variety of AMF2 instruments will be deployed on the valley floor, as indicated in Table 4. The Valley Floor site will remain accessible by road vehicles during the winter. The role of the Valley Floor site will be to document the local meteorology by conducting twice daily radiosonde measurements and hosting the $915 \mathrm{MHz}$ wind profiler. 


\section{Other Instrument Sites}

Additional instruments will be located at other locations on the mountain to measure solar and infrared radiation fluxes, precipitation, and winds as listed in missing reference. These instruments will help provide a measure of local-scale variability.

We now discuss in greater detail the various instruments, associated measurements, and other operational considerations at the various measurement sites. Locations and distances between the sites are listed in Table 1.

Table 1. Site locations and distances.

\begin{tabular}{|l|l|l|l|l|l|l|l|}
\hline \multicolumn{1}{|c|}{ Site } & Latitude & Longitude & Elevation(m) & $\begin{array}{c}\text { Hor dist } \\
\text { to S_C }\end{array}$ & $\begin{array}{c}\text { Hor dist } \\
\text { to S_M }\end{array}$ & $\begin{array}{l}\text { Hor dist } \\
\text { to S_MT }\end{array}$ & $\begin{array}{c}\text { Hor dist } \\
\text { to S_A }\end{array}$ \\
\hline Valley Floor & 40.4622 & 106.8169 & 2078.0 & 0.0 & 3.73 & 6.18 & 2.66 \\
\hline Thunderhead & 40.4542 & 106.7731 & 2759 & 3.73 & 0.0 & 2.44 & 1.17 \\
\hline $\begin{array}{l}\text { Storm Peak } \\
\text { Laboratory }\end{array}$ & 40.4551 & 106.7445 & 3203 & 6.18 & 2.44 & 0.0 & 3.60 \\
\hline Christie Peak & 40.4546 & 106.7874 & 2440.0 & 2.66 & 1.17 & 3.60 & 0.00 \\
\hline
\end{tabular}

\subsection{Thunderhead}

The Thunderhead site will be located immediately north of the Thunderhead ski lodge near the offloading location of the Steamboat Gondola. This site will house most of the principal instruments used for cloud property remote sensing as listed in Table 2 .

Table 2. Thunderhead instruments.

\begin{tabular}{|l|l|l|l|}
\hline \multicolumn{1}{|c|}{ Instrument } & \multicolumn{1}{|c|}{ Measurement } & Proposed Location & \multicolumn{1}{c|}{ Support Needed } \\
\hline $\begin{array}{l}\text { Scanning W-Band Cloud } \\
\text { Radar (SWACR) }\end{array}$ & $\begin{array}{l}\text { In-cloud Doppler } \\
\text { moments and full } \\
\text { Spectra (in the vertical } \\
\text { mode), depolarization } \\
\text { ratios }\end{array}$ & Top of Ops Van & $\begin{array}{l}\text { Site prep for Van or } \\
\text { platform }\end{array}$ \\
\hline Micropulse Lidar (MPL) & $\begin{array}{l}\text { Aerosol, cloud } \\
\text { backscatter, cloud base } \\
\text { (532 nm) }\end{array}$ & Inside Ops Van & Snow removal from roof \\
\hline $\begin{array}{l}\text { High Spectral Resolution } \\
\text { Lidar (HSRL) }\end{array}$ & $\begin{array}{l}\text { Cloud and aerosol } \\
\text { optical depth, } \\
\text { backscatter }\end{array}$ & Inside Ops Van & Snow removal from roof \\
\hline $\begin{array}{l}\text { Atmospheric Emitted } \\
\text { Radiance Interferometer } \\
\text { (AERI) }\end{array}$ & $\begin{array}{l}\text { Atmospheric radiance, } \\
\text { temperature }\end{array}$ & Inside Ops Van & $\begin{array}{l}\text { Snow removal from } \\
\text { side of van }\end{array}$ \\
\hline $\begin{array}{l}\text { Microwave Radiometer } \\
\text { (MWR) }\end{array}$ & $\begin{array}{l}\text { Integrated atmospheric } \\
\text { water vapor }\end{array}$ & Top of Ops Van & Access when snowy \\
\hline
\end{tabular}


Table 2. (Cont.)

\begin{tabular}{|l|l|l|l|}
\hline \multicolumn{1}{|c|}{ Instrument } & \multicolumn{1}{|c|}{ Measurement } & Proposed Location & \multicolumn{1}{c|}{ Support Needed } \\
\hline $\begin{array}{l}\text { Multifilter Rotating } \\
\text { Shadowband (MFRSR) } \\
\text { Radiometer }\end{array}$ & $\begin{array}{l}\text { Optical depth, } \\
\text { downwelling irradiance } \\
\text { at 6 wavelengths }\end{array}$ & Top of Ops Van & Access when snowy \\
\hline $\begin{array}{l}\text { Basic Radiometer } \\
\text { System (RadSys) }\end{array}$ & $\begin{array}{l}\text { Broadband downwelling } \\
\text { global, direct, diffuse } \\
\text { SW; LW }\end{array}$ & $\begin{array}{l}\text { Top of Ops Van or } \\
\text { nearby Lift }\end{array}$ & $\begin{array}{l}\text { Data comms, access if } \\
\text { on Lift }\end{array}$ \\
\hline $\begin{array}{l}\text { Infrared Surface } \\
\text { Temperature (IRT) }\end{array}$ & $\begin{array}{l}\text { Infra-red surface skin } \\
\text { Temp }\end{array}$ & $\begin{array}{l}\text { Pole/twr on Ops Van } \\
\text { side? }\end{array}$ & \\
\hline Data System & $\begin{array}{l}\text { Instrument systems, } \\
\text { data archive }\end{array}$ & Inside Ops Van & \\
\hline
\end{tabular}

The MPL and high spectral resolution lidar will operate from within the OPS van, pointing vertically through portholes located in the van's roof; the AERI, also operating from within the OPS van, has its primary sensors and blackbodies located on the outside of the OPS van with the interferometer located inside (see Figure 2). The Scanning W-Band ARM Cloud Radar (SWACR) will be located on the OPS van roof at the Southeastern edge (Figure 2), with electronics support immediately below, inside the OPS van. The MFRSR, MWR, and infrared thermometer (IRT) will be mounted on a platform on the OPS van roof, at the opposite end from the SWACR. Care must be taken to ensure that the vertical plane for tip calibrations for the MWR intersects as little terrain as possible.

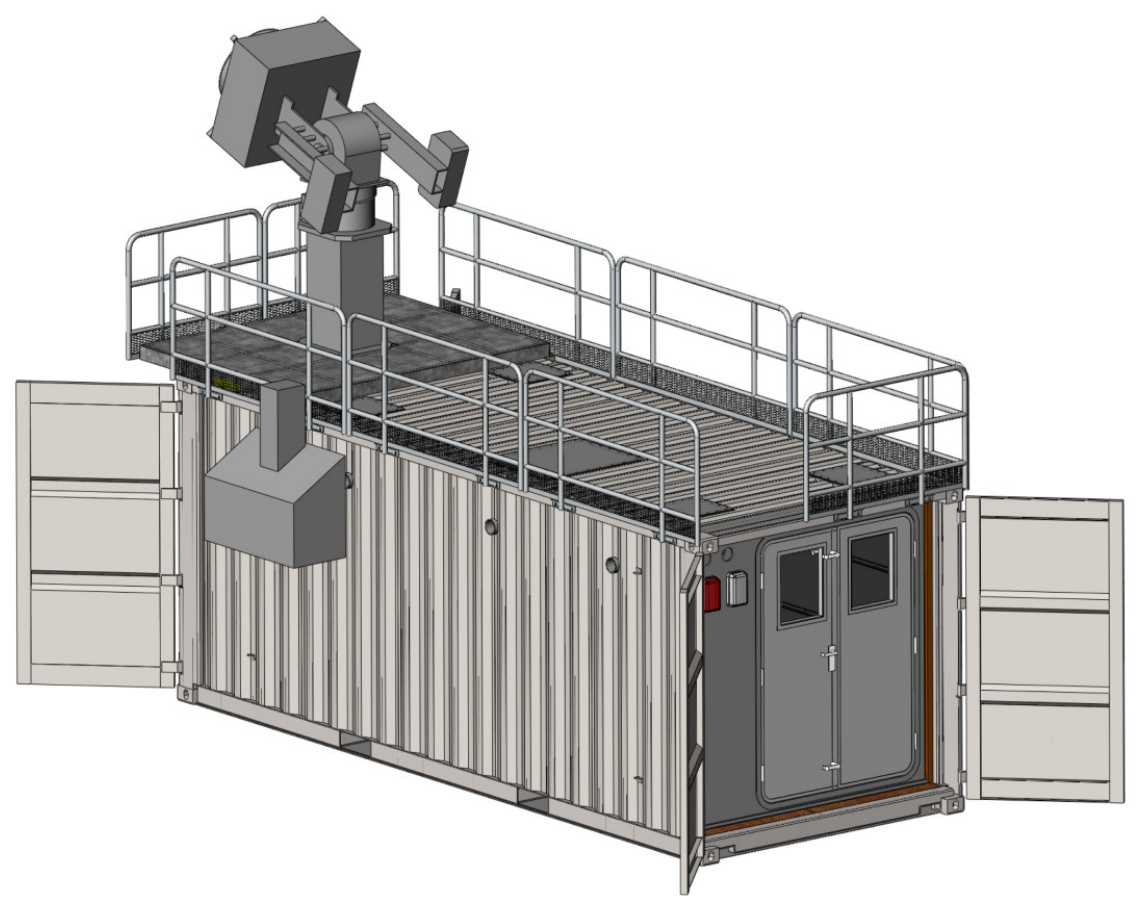

Figure 2. Depiction of the OPS van to be located at the Thunderhead Lodge. SWACR is mounted on the roof at one end and AERI enclosure can be seen mounted to side of van. Portholes in roof for high spectral resolution lidar and MPL are located on near side. The MFRSR, MWR, and IRT will be located roughly at top of railing at end opposite the SWACR. 
Initially, Long's RadSys will be positioned on the OPS van roof, opposite the SWACR, as illustrated in Figure 3. Figures 4 and 5 illustrate the likely terrain influences on these measurements (and the MFRSR) as can best be estimated at this time.

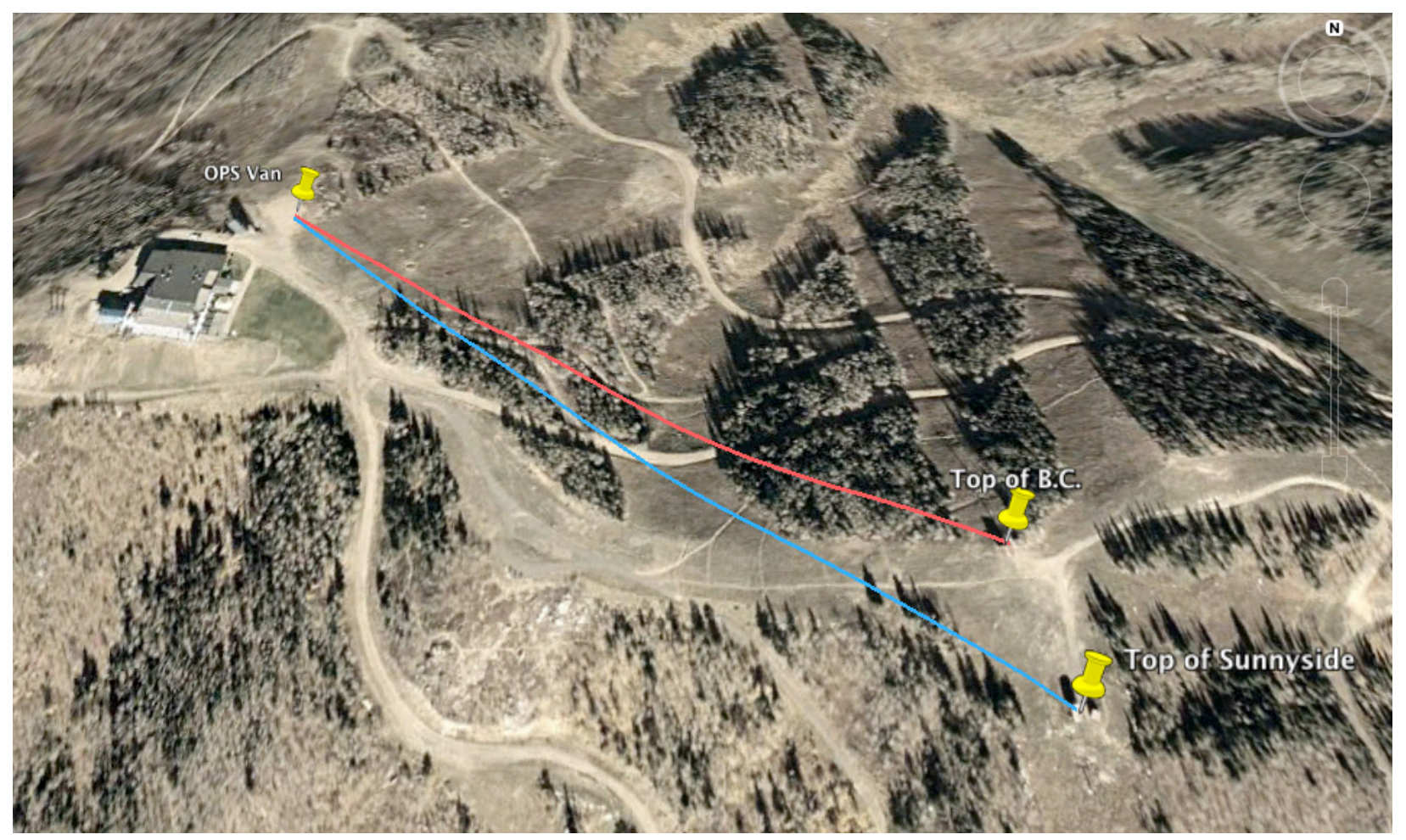

Figure 3. View of Thunderhead and possible locations of SWACR corner reflector (Top of Burgess Creek (B.C.) chair) and Long's Radsys (Top of Sunnyside). Both sites are visible from the OPS van and approximately 440-500 m distant.

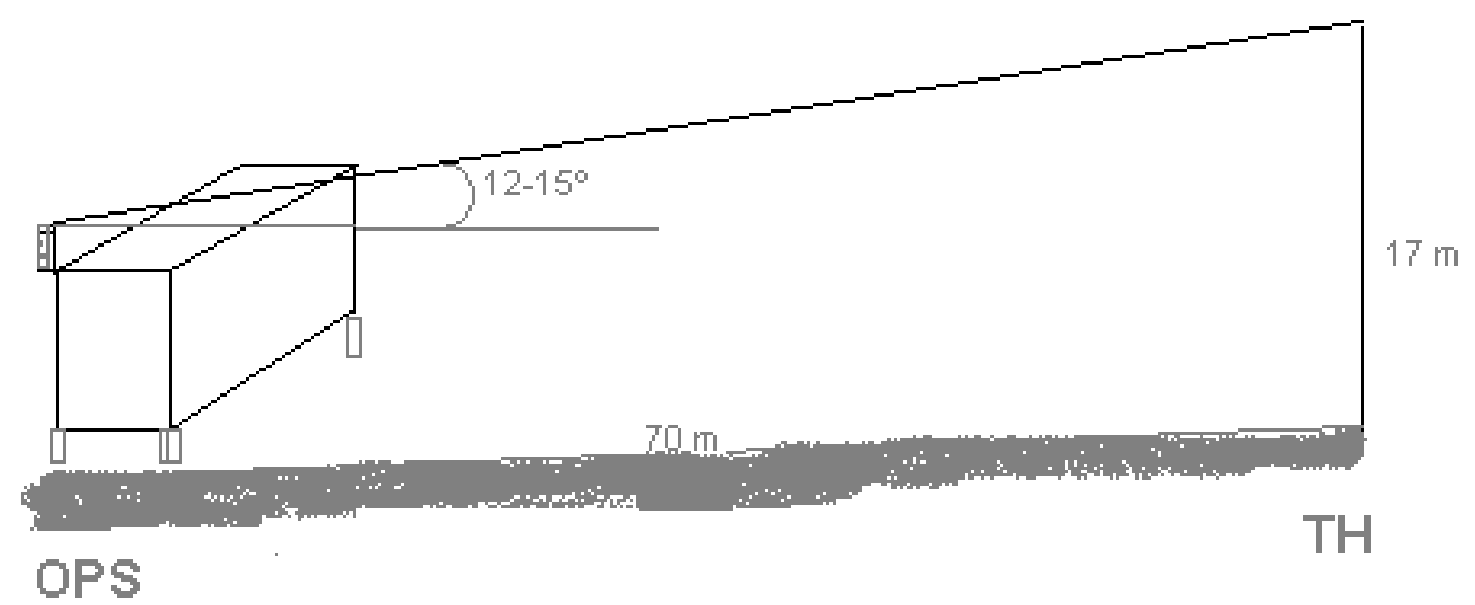

Figure 4. Sketch of structure impediments to radiometry field of view from top of OPS van. Thunderhead Lodge actually extends through 20 degrees horizontal arc and will block the setting sun during part of the period. 


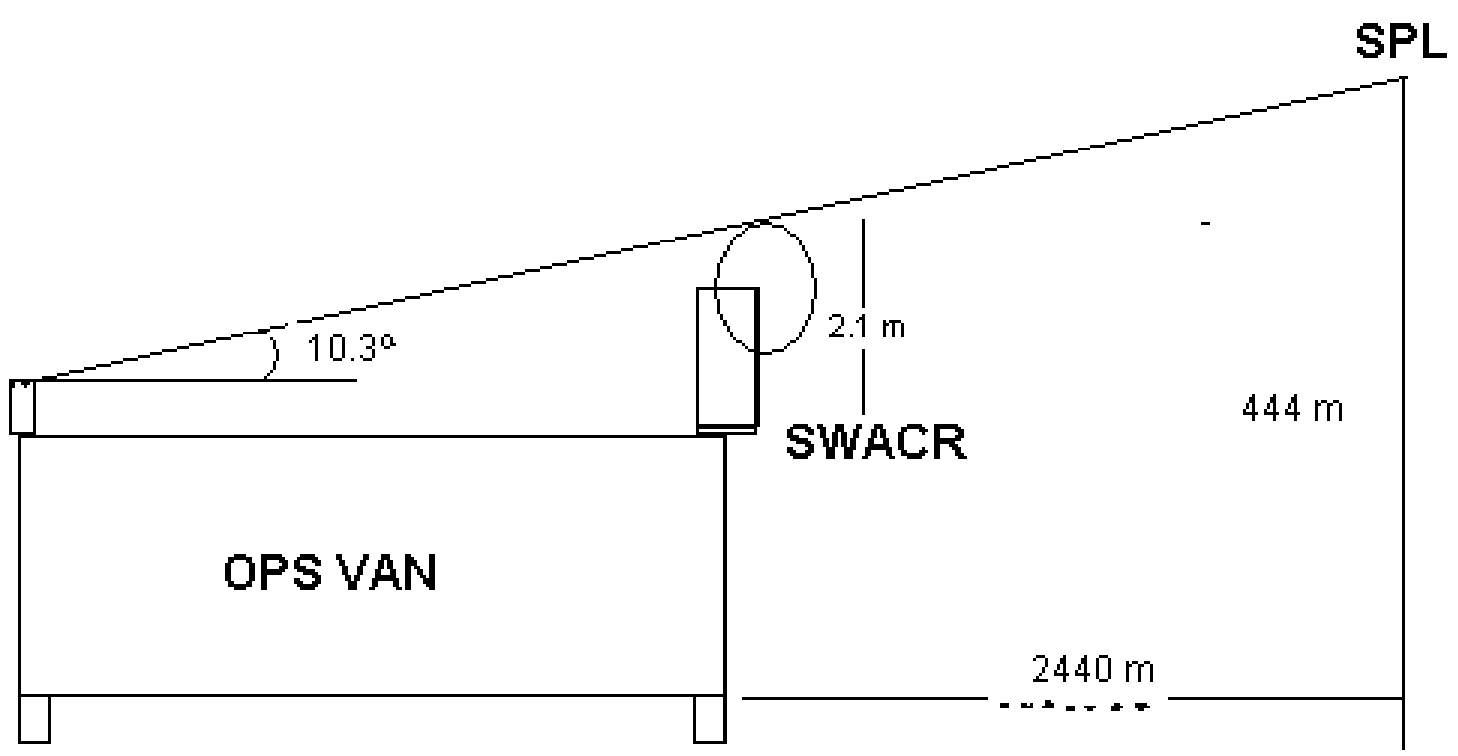

Figure 5. Sketch of topographical impediment of mountains to east of Thunderhead site. In order to keep the SWACR within the area blocked by the Mountains, the radiometry platform needs to be at least $1 \mathrm{~m}$ above the roof of the OPS van.

\subsubsection{Possible Sitting Adjustments}

Under normal operating scenarios, the SWACR is positioned to point at a corner reflector at regular intervals for calibration purposes. The corner reflector generally needs to be well above the surface and separated from other potential reflectors, in the far field, and capture most, if not all, of the main lobe of the radar transmission. It is not likely that a tower for this purpose can be erected on the Ski Corporation property. It may be possible, however to place a corner reflector at the top of the B.C. lift, located $440 \mathrm{~m}$ distant at 123 deg from the SWACR (Figure 3); it is likely that this would require a mast attached to the lift to clear the reflector from objects. Another possibility is to place a corner reflector at SPL (doubtful because of the large separation). These options will be explored during installation.

If it is not satisfactory to locate Long's RadSys at the OPS van because of limitations in viewing the southern sky near sunset, a site with excellent views of the sky is located at the top of the Sunnyside lift, located $502 \mathrm{~m}$ at $130 \mathrm{deg}$ from the OPS van. The top of the lift house is a flat area, accessible by ladder. If wireless communication and procedures for safely accessing the radiometers daily (at least) can be established, this option will be addressed during installation as well.

\subsubsection{Power and Local Data Flow}

Power will be provided to the OPS van from a 480 VAC 3-phase power drop immediately north of the OPS van. All instruments located within or on the OPS van will be powered from within the van. Data flow within the Thunderhead site and instrument control and monitoring will use wireless or wired communications, as appropriate between the Local Data System and individual instrument systems. If Long's RadSys is located at the top of Sunnyside lift house data communications will be wireless. Because this is a relatively long span, some data may need to be downloaded by hand at times. This will be a decision made on-site. See Section 5.0 for a description of data transfer among the STORMVEX sites and to the world at large. 


\subsubsection{Site Operation}

All the instruments located at this site, with the exception of the SWACR, will operate continuously and will not change their operating parameters with atmospheric conditions. The SWACR will have multiple operational modes depending on the existing and predicted conditions. All the instrument platforms will be monitored remotely at least daily by AMF2 personnel both within the immediate vicinity and at Argonne. At least two AMF2 personnel will be present at the STORMVEX location and will visit the Thunderhead site at least daily. They will check all instruments, clean all radiometry domes, and perform any needed maintenance as required during these visits. These visits will be scheduled to be during regular ski area operation hours ( approximately 8:30 a.m.-4:30 p.m. local time (LT), depending on time of year). It will be particularly important to maintain the top of the OPS van as clear of snow as possible so as to ensure maximum safety in accessing the instruments on the trailer roof. In the case where site visits are mandated at other times, coordination with ski patrol and SPL personnel will be necessary to enable access to the site.

During cloud and precipitation events, the SWACR will repeatedly perform a sequence of scan and pointing measurements as described in Section 3.0.

\subsection{Christie Peak}

Christie Peak, located several hundred meters below and just west of the Thunderhead site, will house the AMF2 Aerosol Observing System. The AOS instruments are listed in Table 3.

Table 3. Christie Peak instruments.

\begin{tabular}{|l|l|l|l|}
\hline \multicolumn{1}{|c|}{ Instrument } & \multicolumn{1}{|c|}{ Measurement } & Proposed Location & \multicolumn{1}{c|}{ Support Needed } \\
\hline $3-\lambda$ Nephelometer (dry) & $\begin{array}{l}\text { Aerosol light absorption at } \\
450,550, \text { and } 700 \mathrm{~nm} \\
(\mathrm{RH}<15 \%)\end{array}$ & $\begin{array}{l}\text { Inside } \\
\text { AMF2-AOS Platform }\end{array}$ & $\begin{array}{l}\text { Weekly calibration } \\
\text { using CO2 }\end{array}$ \\
\hline $3-\lambda$ Nephelometer (wet) & $\begin{array}{l}\text { Aerosol light absorption at } \\
450,550, \text { and } 700 \mathrm{~nm} \\
(\mathrm{RH} 40-90 \%)\end{array}$ & $\begin{array}{l}\text { Inside } \\
\text { AMF2-AOS Platform }\end{array}$ & $\begin{array}{l}\text { Weekly calibration } \\
\text { using CO2; water as } \\
\text { needed }\end{array}$ \\
\hline $\begin{array}{l}\text { 3- } \lambda \text { Particle Soot } \\
\text { Absorption Photometer } \\
\text { (PSAP) }\end{array}$ & $\begin{array}{l}\text { Aerosol light absorption at } \\
450,550, \text { and } 700 \mathrm{~nm}\end{array}$ & $\begin{array}{l}\text { Inside } \\
\text { AMF2-AOS Platform }\end{array}$ & Filter changes (daily) \\
\hline $\begin{array}{l}\text { Hygroscopicity Tandem } \\
\text { Differential Mobility } \\
\text { Analyzer (HTDMA) }\end{array}$ & $\begin{array}{l}\text { Hygroscopic particle } \\
\text { growth }\end{array}$ & $\begin{array}{l}\text { Inside } \\
\text { AMF2-AOS Platform }\end{array}$ & $\begin{array}{l}\text { Water/butanol as } \\
\text { needed }\end{array}$ \\
\hline $\begin{array}{l}\text { Cloud Condensation Nuclei } \\
\text { (CCN) counter }\end{array}$ & $\begin{array}{l}\text { CCN activity at two super } \\
\text { saturations }\end{array}$ & $\begin{array}{l}\text { Inside } \\
\text { AMF2-AOS Platform }\end{array}$ & $\begin{array}{l}\text { Water/butanol as } \\
\text { needed }\end{array}$ \\
\hline $\begin{array}{l}\text { Condensation Particle } \\
\text { Counter (CPC) }\end{array}$ & Particle counting $>10 \mathrm{~nm}$ & $\begin{array}{l}\text { Inside } \\
\text { AMF2-AOS Platform }\end{array}$ & Butanol as needed \\
\hline Trace Gas (Ozone) & Ambient ozone burden & $\begin{array}{l}\text { Inside } \\
\text { AMF2-AOS Platform }\end{array}$ & Monthly filter changes \\
\hline Meteorological Data & $\begin{array}{l}\text { Temperature; wind } \\
\text { speed; wind direction; } \\
\text { humidity; pressure; } \\
\text { rainfall }\end{array}$ & $\begin{array}{l}\text { Inside } \\
\text { AMF2-AOS Platform }\end{array}$ & none \\
\hline
\end{tabular}


Table 3. (Cont.)

\begin{tabular}{|l|l|l|l|}
\hline \multicolumn{1}{|c|}{ Instrument } & \multicolumn{1}{|c|}{ Measurement } & Proposed Location & \multicolumn{1}{c|}{ Support Needed } \\
\hline $\begin{array}{l}\text { Single Particle Soot } \\
\text { Photometer (SP2) }\end{array}$ & $\begin{array}{l}\text { Black Carbon mass } \\
\text { concentration and size } \\
\text { distribution }\end{array}$ & $\begin{array}{l}\text { Inside } \\
\text { AMF2-AOS Platform }\end{array}$ & $\begin{array}{l}\text { Data transfers as } \\
\text { needed }\end{array}$ \\
\hline Data System & $\begin{array}{l}\text { Instrument systems, data } \\
\text { archive }\end{array}$ & $\begin{array}{l}\text { Inside } \\
\text { AMF2-AOS Platform }\end{array}$ & $\begin{array}{l}\text { Snow removal as } \\
\text { needed }\end{array}$ \\
\hline $\begin{array}{l}\text { Multifilter Rotating } \\
\text { Shadowband Radiometer } \\
\text { (MFRSR) }\end{array}$ & $\begin{array}{l}\text { Direct normal, Diffuse and } \\
\text { Total horizontal solar } \\
\text { irradiance at 415, 500, } \\
615,673,870,940 \mathrm{~nm} .\end{array}$ & $\begin{array}{l}\text { Roof of AOS } \\
\text { platform }\end{array}$ & \\
\hline
\end{tabular}

The ARM Mobile Facility Aerosol Observing System (AMF2-AOS) platform will be located at Christie Peak between the Thunderhead gondola and the Christie Peak Express lifts, providing a site that overlooks the Steamboat Springs valley (Figure 6). The site location is shown in Figure 1. Proximity to the Christie Peak Express ski lift provides ready access to the AOS container. Additionally, this location will require appropriate security to ensure that skiers and casual onlookers do not interfere with ongoing measurements during the STORMVEX campaign.

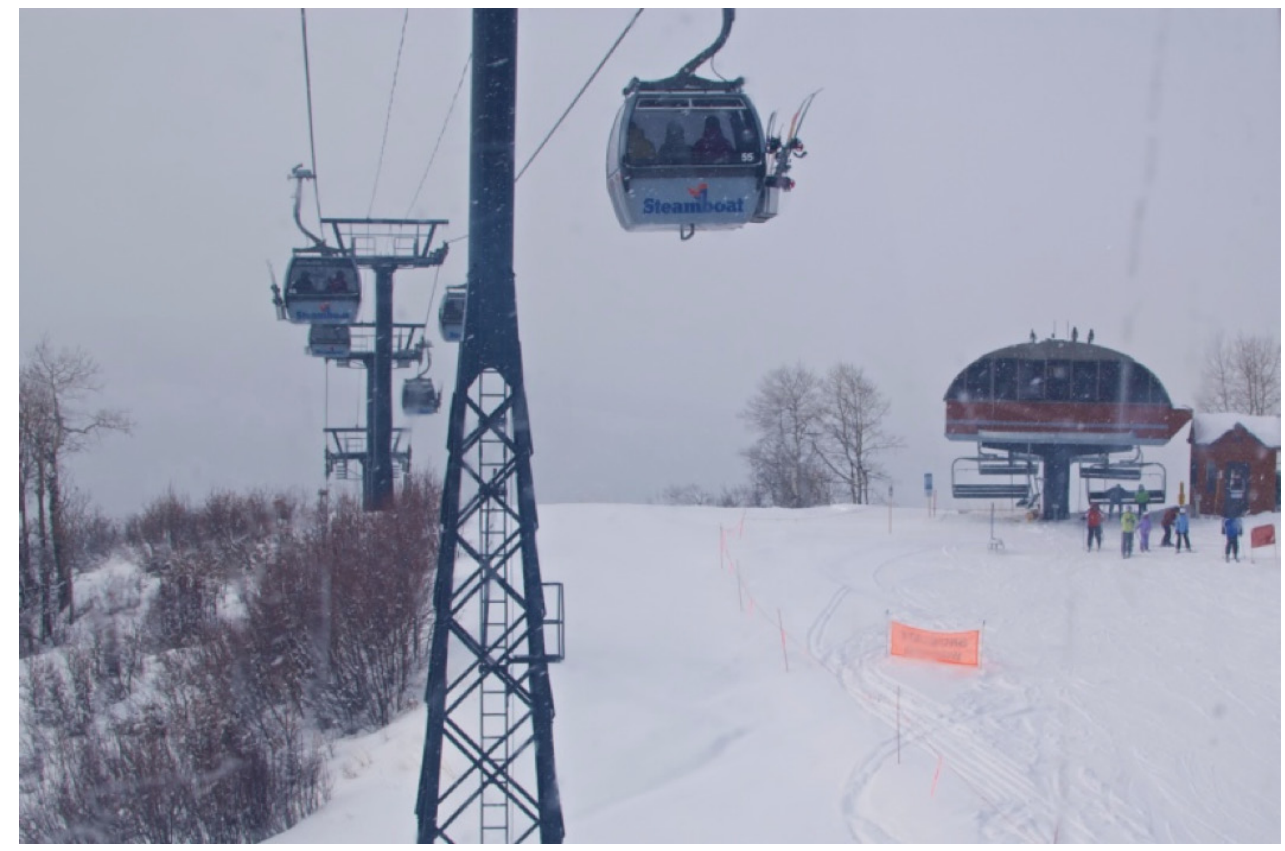

Figure 6. View of the AMF2-AOS site at Christie Peak as seen from the Thunderhead gondola. The AOS platform will be staged in between the Thunderhead gondola and the Christie Peak express ski lift.

The AMF2-AOS is a new generation of mobile ARM platform for in situ aerosol measurements at the surface. This platform measures aerosol optical properties to better understand how particles interact with solar radiation and influence the earth's radiation balance. The principal measurements are those listed in Table 3 and include: aerosol absorption and scattering coefficients as a function of radiation wavelength; 
particle number concentration; size distribution, hygroscopic growth, and inorganic chemical composition. These measurements are then used for estimating parameters used in radiative forcing calculations, such as the aerosol single scattering albedo (red-green-blue), asymmetry parameter, mass scattering efficiency, CCN activity, and hygroscopic growth (fRH).

Shown in Figure 7 is the ARM AMF1 that is currently deployed in the Azores and from which the AMF2-AOS was modeled. The 8-inch inlet extends up to $10 \mathrm{~m}$ above ground level (AGL) and will have a stack flow rate of nominally 1000 LPM (through active control of the blower motor). Within the 8-inch main inlet stack is a 2-inch sample inlet that is be terminated into a 5-pick off manifold, as depicted on the right side of Figure 7. Each instrument pickup will have a 30 LPM sample flow.
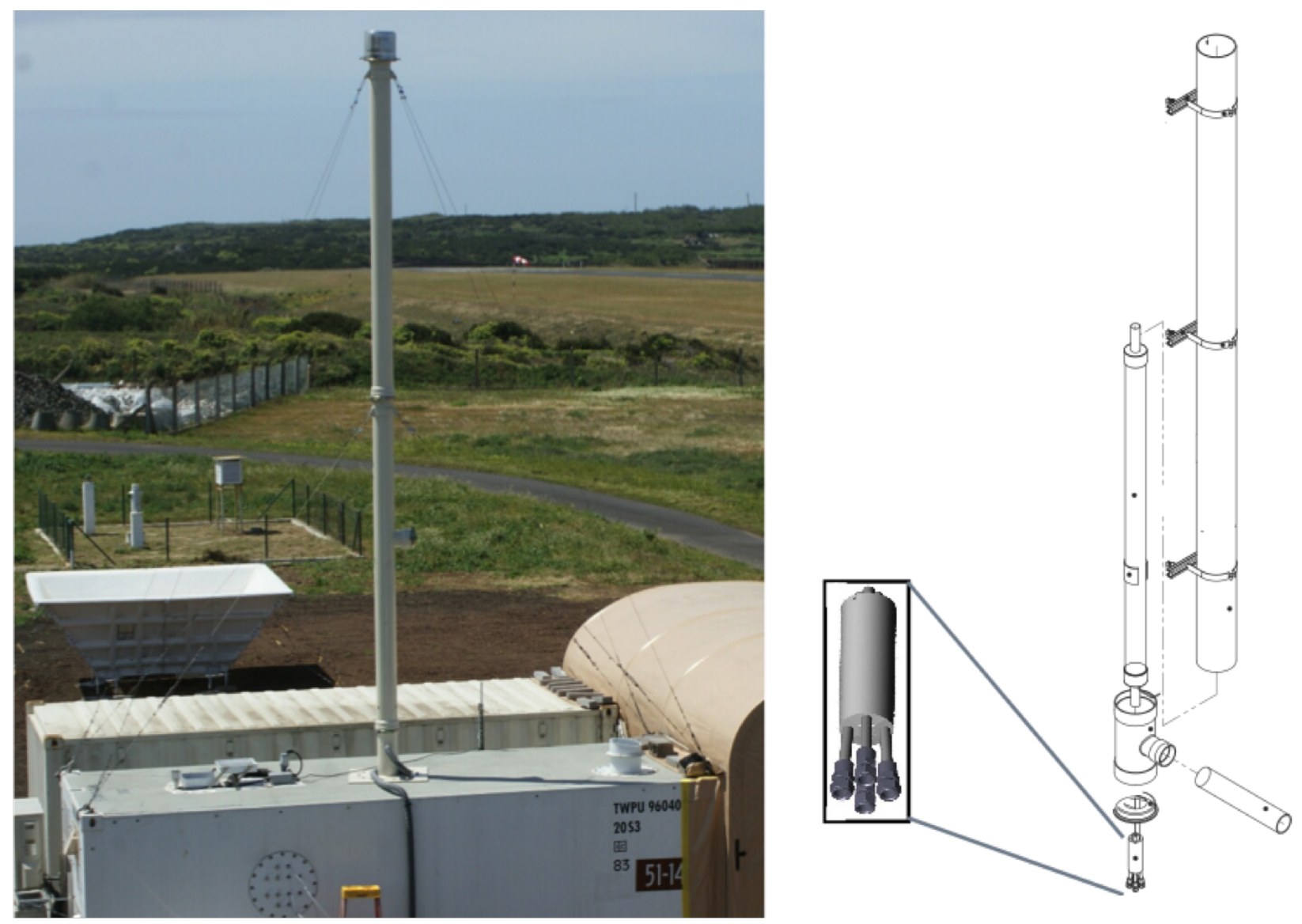

Figure 7. On the left is a photograph of ARM AMF1-AOS currently deployed in the Azores, and on the right is a schematic of the aerosol inlet with the five-port sample manifold enlarged. See text for more details.

\subsubsection{Power and Local Data Flow}

Power for the AOS platform - 110/220 VAC power, 100 Amp single-phase service - will be provided by the junction box on a supporting tower of the Thunderhead lift. This junction box is show in Figure 8 and is positioned nominally $10-15 \mathrm{~m}$ from the AOS staging site. All instruments located within or on the AOS van will be powered from within the van. 


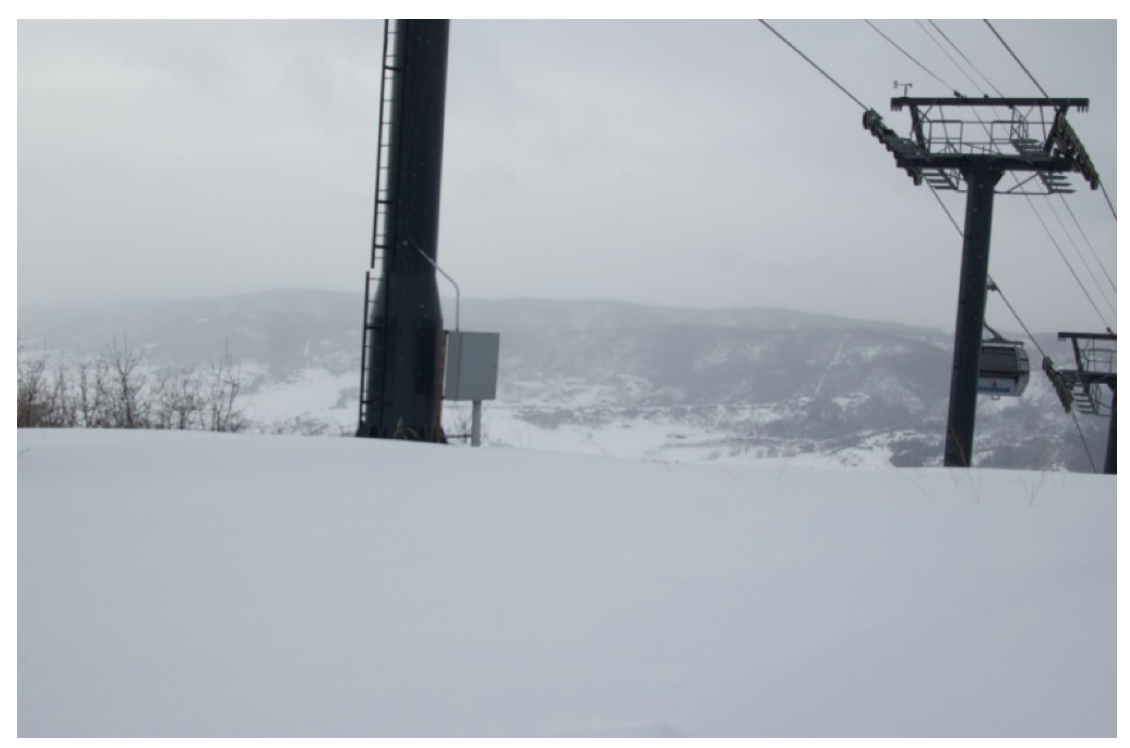

Figure 8. Junction box for AOS power.

Data flow within the Christie Peak site and instrument control and monitoring will use wireless or wired communications, as appropriate between the Local Data System) and individual instrument systems. See Section 5.0 for a description of data transfer among the STORMVEX sites and to the world at large.

\subsubsection{Site Operation}

All the instruments located at this site will operate continuously and will not change their operating parameters with atmospheric conditions. The AOS platform will be monitored remotely at least daily by AMF2 personnel within the immediate vicinity and by AOS personnel at Brookhaven. At least two AMF2 personnel will be present at the STORMVEX location and will visit the Christie Peak site at least daily. They will check the status of all instruments and perform any needed maintenance as outlined on the AOS daily maintenance checklist. These visits will be scheduled to be during regular ski area operation hours ( 8:30-16:30 LT, depending on time of year). It is to be noted that the top of the AOS van must be kept free of snow so as to ensure maximum safety when accessing the MFRSR on the trailer roof. In the case where site visits are mandated at other times, coordination with ski patrol and SPL personnel will be necessary to enable access to the site.

Daily activities for the AOS platform include: (1) filter changes on the PSAP; (2) water, as needed, for the humidgraph ('wet' nephelometer); (3) butanol, as needed, for the Condensation Particle Counter (CPC); (4) water/butanol, as needed, for the Humidified Tandem Differential Mobility Analyzer; (5) ozone filter change (biweekly); water/butanol, as needed, for the CCN; (6) archiving data; (7) shoveling snow around the entrance and rear vestibule (as needed); and (8) logging activities in and around the area (e.g., weekly testing of diesel generators). A computerized log will be made available for item 8.

\subsection{Valley Floor}

It is anticipated that the Valley Floor site will be located immediately north of the Yampa Valley Medical Center (see Figure 1). From this location one has a direct line of sight to all major STORMVEX sampling locations, including Thunderhead, Christie Peak, and Storm Peak Lab. 
The AMF2 instruments anticipated to be included at the Valley Floor site are listed in Table 4. In addition, several guest instruments will also be located at the Valley Floor site and are included in Table 4.

Table 4. Instrumentation at Valley Floor site.

\begin{tabular}{|c|c|c|c|}
\hline Instrument & Measurement & Proposed Location & Support Needed \\
\hline $\begin{array}{l}\text { Radar Wind Profiler } \\
\text { (RWP) }\end{array}$ & Winds, backscatter & $\begin{array}{l}\text { East of GP Van within } \\
20 \mathrm{~m}\end{array}$ & $\begin{array}{l}\text { Tie Downs or weights for } \\
\text { guy wires }\end{array}$ \\
\hline Ceilometer (VCEIL) & Cloud base, aerosols & $\begin{array}{l}\text { East of GP Van within } \\
10 \mathrm{~m}\end{array}$ & Tripod tie-downs \\
\hline SKYRAD & $\begin{array}{l}\text { Broadband SW, infrared, } \\
\text { UV downwelling } \\
\text { irradiance }\end{array}$ & $\begin{array}{l}\text { East of GP Van } \sim 50 \mathrm{~m} \\
\text { Elevated Stand }\end{array}$ & $\begin{array}{l}\text { Radiometer stand tie- } \\
\text { downs }\end{array}$ \\
\hline GNDRAD & $\begin{array}{l}\text { Broadband SW, infrared } \\
\text { upwelling irradiance }\end{array}$ & $\begin{array}{l}\text { East of GP Van } \sim 50 \mathrm{~m} \\
\text { from } 10 \mathrm{~m} \text { tower }\end{array}$ & Tower \\
\hline $\begin{array}{l}\text { Total Sky Imager } \\
\text { (TSI) }\end{array}$ & Cloud fraction & $\begin{array}{l}\text { East of GP Van } \sim 50 \mathrm{~m} \\
\text { Elevated Stand }\end{array}$ & \\
\hline $\begin{array}{l}\text { Balloon-borne } \\
\text { Sounding System } \\
\text { (BBSS) }\end{array}$ & $\begin{array}{l}\text { Wind, Temp, } \mathrm{RH} \\
\text { atmospheric profile }\end{array}$ & $\begin{array}{l}\text { Helium beside GP Van } \\
\text { Launch from field as } \\
\text { appropriate }\end{array}$ & $\begin{array}{l}\text { Helium location access } \\
\text { to field through snow }\end{array}$ \\
\hline Surface Fluxes (ECOR) & $\begin{array}{l}\text { Heat, Momentum, Water } \\
\text { Vapor, CO2 surface } \\
\text { fluxes }\end{array}$ & $\begin{array}{l}\text { East of GP Van } \sim 50 \mathrm{~m} \\
\text { from tripod/tower }\end{array}$ & $\begin{array}{l}\text { Access to instrument } \\
\text { through snow }\end{array}$ \\
\hline Surface Met (SMOS) & $\begin{array}{l}10 \mathrm{~m} \text { winds, } \\
\text { temperature, relative } \\
\text { humidity, precipitation }\end{array}$ & $\begin{array}{l}\text { East of GP Van } \sim 50 \mathrm{~m} \\
\text { from tower }\end{array}$ & \\
\hline $\begin{array}{l}\text { Infra Red Sfc } \\
\text { Temperature (IRT) }\end{array}$ & $\begin{array}{l}\text { Surface skin } \\
\text { temperature }\end{array}$ & $\begin{array}{l}\text { East of GP Van } \sim 50 \mathrm{~m} \\
\text { from tower }\end{array}$ & Height TBD \\
\hline Local Data System & $\begin{array}{l}\text { Instrument } \\
\text { communication }\end{array}$ & GP Van Inside trailer & $\begin{array}{l}\text { Virtual Comms to Data } \\
\text { System }\end{array}$ \\
\hline $\begin{array}{l}\text { JPL } 94 \text { GHz Cloud } \\
\text { Radar (ACR) }\end{array}$ & $\begin{array}{l}\text { Scanning W-Band } \\
\text { Radar Reflectivity }\end{array}$ & JPL Supplied Trailer & Steve Dinardo, JPL \\
\hline MMCR & $\begin{array}{l}\text { Vertically pointing Ka- } \\
\text { Band Doppler Radar } \\
\text { Spectra }\end{array}$ & & \\
\hline $\begin{array}{l}\text { Scanning ARM Cloud } \\
\text { Radar (SACR) }\end{array}$ & $\begin{array}{l}\text { Scanning X- and Ka- } \\
\text { Band Doppler Radar } \\
\text { Spectra }\end{array}$ & & \\
\hline
\end{tabular}

\subsubsection{Power and Local Data Flow}

Power will be provided from a 110/220 VAC power drop north of the hospital. 100-amp single phase service will be provided to an 8 X 20 foot van that will house the data system, radar wind profiler (RWP), Vaisala ceilometer, and balloon-borne sounding system (BBSS) electronics system. A second 60-amp service will be supplied to a power module located about $50 \mathrm{~m}$ from the van. The power module will supply a RAD module and a MET module that in turn supports the IRT, TSI, SKYRAD, GNDRAD, ECOR, and SMOS. 
Data flow within the Valley Floor site and instrument control and monitoring will use wireless communications between the local data system) and individual modules. See Section 5.0 for a description of data transfer among the STORMVEX sites and to the world at large.

\subsubsection{Site Operation}

All the instruments located at this site, with the exception of the RWP and BBSS, will operate continuously and will not change their operating parameters with atmospheric conditions. The RWP, while operating continuously, will be operated in two different modes, depending on present or predicted weather conditions. In clear or non-precipitating conditions, it will operate in a manner similar to the operation of the currently operating ARM wind profilers: a high and low power alternating pattern with five pointing angles at each direction, producing averaged wind profiles hourly. In precipitating conditions, or special situations, it will operate in a vertical-only mode with shorter dwell times $(5 \mathrm{sec})$ and averaging times (5-10 min) and expanded spectra to increase vertical velocity resolution.

The BBSS system will normally operate on a two launch per day schedule, at 0800 and $1500 \mathrm{LT}$ (1500 and 2200 GMT). Under certain circumstances, as determined by the principal investigators, this schedule may be altered. It is anticipated that volunteers from the community will be able to assist with this operation.

All the instrument platforms will be monitored remotely at least daily by AMF2 personnel both within the immediate vicinity and at Argonne. At least two AMF2 personnel will be present at the STORMVEX location and will visit the Valley Floor site at least daily. They will check all instruments, clean all radiometry domes, and perform any needed maintenance as required during these visits.

\subsection{Storm Peak Lab}

DRI operates a variety of instruments at SPL, located on the summit of Mt. Werner (Figure 1), as listed in Table 5. This site will also host additional cloud microphysical probes being supplied by SPEC Inc., as well as several guest instruments (including additional precipitation measurements) discussed later in this document (Table 6). (1) TSI Scanning Mobility Particle Sizer) (model 3936) coupled with a TSI model 3022A CPC; (2) stand-alone TSI model 3010 CPC for particles with diameters larger than $10 \mathrm{~nm}$; (3) stand-alone TSI model 3025 CPC for particles with diameters larger than $3 \mathrm{~nm}$; (4) TSI model 3321 Aerodynamic Particle Sizer for particles with diameters larger than $540 \mathrm{~nm}$; (5) Droplet Measurement Technologies, Inc. (DMT) CCN-100 counter; (6) Yankee Visible and UV multifilter rotating shadowband radiometer, (7) trace gases including ozone, carbon dioxide, carbon monoxide, Elemental Gaseous Phase Mercury; and (8) complete meteorological station, including temperature, pressure, wind speed and direction, and relative humidity with Campbell Scientific, Inc., Met One and Vaisala sensors interfaced to a Campbell Scientific, Inc. CR10 data logger. Instruments are controlled by computers linked in a secure intranet with broadband communication to DRI and the outside world. Most instrumentation can be monitored remotely via the Storm Peak website. 
Table 5. SPL instrumentation.

\begin{tabular}{|c|c|c|c|c|c|c|}
\hline $\begin{array}{c}\text { SPL } \\
\text { Instruments }\end{array}$ & Measurement & Location & $\begin{array}{l}\text { Operation } \\
\text { Plans }\end{array}$ & $\begin{array}{c}\text { Calibration } \\
\text { History/ } \\
\text { Plans }\end{array}$ & $\begin{array}{c}\text { Level } 1 \\
\text { Data } \\
\text { Availability }\end{array}$ & $\begin{array}{c}\text { Level } 2 \\
\text { Plans }\end{array}$ \\
\hline PIP & $\begin{array}{l}\text { Raw data } \\
\text { needed } \\
100 \text { microns } \\
\text { to } 6.5 \mathrm{~mm} \text {. }\end{array}$ & SPL & $\begin{array}{l}\text { Whenever } \\
\text { particles } \\
\text { are } \\
\text { around }\end{array}$ & $\begin{array}{l}\text { Cal by dmt } \\
\text { prior. }\end{array}$ & $\begin{array}{l}\text { Raw data } \\
\text { will be } \\
\text { provided }\end{array}$ & $\begin{array}{l}\text { Processing } \\
\text { in plans. }\end{array}$ \\
\hline FSSP & $\begin{array}{l}\text { Psd 1-50 } \\
\text { microns }\end{array}$ & SPL & $\begin{array}{l}\text { Whenever } \\
\text { particles } \\
\text { are } \\
\text { around }\end{array}$ & $\begin{array}{l}\text { Calibrated } \\
\text { by dmt }\end{array}$ & $\begin{array}{l}\text { Raw data to } \\
\text { be } \\
\text { preserved }\end{array}$ & $\begin{array}{l}\text { Size } \\
\text { distributions }\end{array}$ \\
\hline CIP & $\begin{array}{l}25-1550 \\
\text { microns }\end{array}$ & SPL & $\begin{array}{l}\text { Whenever } \\
\text { particles } \\
\text { are } \\
\text { around }\end{array}$ & $\begin{array}{l}\text { Calibrated } \\
\text { by DMT } \\
\text { prior }\end{array}$ & $\begin{array}{l}\text { Raw data to } \\
\text { be } \\
\text { preserved }\end{array}$ & $\begin{array}{l}\text { Size } \\
\text { Distributions }\end{array}$ \\
\hline CCN counter & $\begin{array}{l}\text { Number per } \\
\mathrm{cm}^{3} \text { per ss } \%\end{array}$ & SPL & $24 / 7$ & $\begin{array}{l}\text { DMT } \\
\text { calibration }\end{array}$ & $\begin{array}{l}\text { Available } \\
\text { upon } \\
\text { request }\end{array}$ & $\mathrm{n} / \mathrm{a}$ \\
\hline $\begin{array}{l}\text { SMPS } \\
\text { (scanning } \\
\text { mobility } \\
\text { particle sizer) }\end{array}$ & $\begin{array}{l}\text { 8-500nm size } \\
\text { distribution }\end{array}$ & SPL & $24 / 7$ & $\begin{array}{l}\text { TSI } \\
\text { calibration } \\
\text { annually; } \\
\text { not } \\
\text { mission- } \\
\text { critical }\end{array}$ & $\begin{array}{l}\text { Available } \\
\text { upon } \\
\text { request }\end{array}$ & \\
\hline $\begin{array}{l}\text { APS } \\
\text { (aerodynamic } \\
\text { particle sizer) }\end{array}$ & $\begin{array}{l}500 \mathrm{~nm} \text { to } 20 \\
\text { microns }\end{array}$ & SPL & $24 / 7$ & $\begin{array}{l}\text { TSI } \\
\text { calibration } \\
\text { annually; } \\
\text { not } \\
\text { mission- } \\
\text { critical }\end{array}$ & & \\
\hline $\begin{array}{l}\text { (U) Cpc (ultra) } \\
\text { (condensation } \\
\text { particle } \\
\text { counter) }\end{array}$ & $\begin{array}{l}\text { Aerosol } \\
\text { concentration } \\
10 \text { and } 3 \mathrm{~nm} \\
\text { cutoffs }\end{array}$ & SPL & $24 / 7$ & $\begin{array}{l}\text { TSI } \\
\text { calibration } \\
\text { annually; } \\
\text { not } \\
\text { mission- } \\
\text { critical }\end{array}$ & & \\
\hline $\begin{array}{l}\text { Trace gasses } \\
\text { (ozone and } \\
\left.\mathrm{CO}_{2}\right)\end{array}$ & & SPL & $24 / 7$ & $\begin{array}{l}\text { Not } \\
\text { mission- } \\
\text { critical }\end{array}$ & & \\
\hline MFRSR & & SPL & $24 / 7$ & & Cal prior & \\
\hline Met & $\begin{array}{l}\text { 5-minute data } \\
\text { uploaded } \\
\text { directly to } \\
\text { WRCC site }\end{array}$ & SPL & $24 / 7$ & & & \\
\hline
\end{tabular}


Table 6. Other guest instruments at SPL.

\begin{tabular}{|l|l|l|l|}
\hline \multicolumn{1}{|c|}{ P.I. } & \multicolumn{1}{|c|}{ Institution } & \multicolumn{1}{c|}{ Name of Instruments } & \multicolumn{1}{c|}{ Dates of Deployment } \\
\hline Dan Cziczo & PNNL & $\begin{array}{l}\text { Ice Nucleation Chamber, Counter- } \\
\text { Flow Virtual Impactor, PALMS, } \\
\text { Aerosol Mass Spectrometer }\end{array}$ & $\begin{array}{l}\text { January 3-February 18 } \\
\text { April 1-May 15 }\end{array}$ \\
\hline Paola Massoli & Aerodyne & CAPS, aerosol extinction & October 15-May 15 \\
\hline Tim Garrett & University of Utah & HYVIS, snowflake probe & Participation uncertain \\
\hline Art Sedlacek & $\begin{array}{l}\text { Brookhaven } \\
\text { National Lab }\end{array}$ & SP2 & October 15-May 15 \\
\hline Larry Berg & PNNL & PSAP, TSI Nephelometer & October 15-May 15 \\
\hline Chuck Long & PNNL & Basic Radiometer System (RadSys) & October 15-May 15 \\
\hline Chuck Long & PNNL & Hemispheric Sky Imager & October 15-May 15 \\
\hline
\end{tabular}

The cloud droplet and snow size spectra from 2-47 $\mu \mathrm{m}, 25-1550 \mu \mathrm{m}$, and 100-6400 $\mu \mathrm{m}$, respectively, are measured with a DMT SPP-100 (modified PMS FSSP-100), DMT Cloud Imaging Probe, and DMT 2D-P (modified PMS OAP 260Y) spectrometer probes mounted on a wind vane to orient both de-iced probes into the wind. The SPP-100 is aspirated and samples cloud droplets nearly iso-kinetically under typical experimental conditions. In ground-based operation, the probe responds only to liquid cloud droplets (Borys et al. 2000). Ice crystal concentrations are based on real-time ambient wind speed measurements. Aerosol size distributions are measured continuously with TSI Scanning Mobility Particle Sizer and an Aerodynamic Particle Sizer for diameters between 0.01-0.8 $\mu \mathrm{m}$ and 0.5-20 $\mu \mathrm{m}$, respectively. Aerosols are sampled through an inlet that excludes cloud droplets and snow and effectively dries the aerosols (Lowenthal et al. 2002). CCN spectra will be measured using a stream-wise continuous-flow DMT CCN100 counter operated over a range of supersaturations down to $0.07 \%$. All instruments will be calibrated and serviced by the manufacturers before the field study.

\subsection{Precipitation Sensors and Other Instruments}

It is anticipated that two NOAH-II all-weather precipitation gauges manufactured by the ETI Instrument Systems (http://www.etisensors.com/noah_ii.htm) will be deployed during the project. These systems will provide the liquid equivalent precipitation accumulation with the resolution of 0.01 ".

One deployment site will be near the Thunderhead location, where routine manual measurements of newly fallen snow are conducted three times daily, and the second deployment site will be at Storm Peak Lab.

A University of Colorado Particle Size and Velocity Disdrometer (PARSIVEL) is planned to be deployed at the SPL site. This device measures the snowflake size and velocity distributions in 32 size bins from 0.062 to $24.5 \mathrm{~mm}$. In addition to the PARSIVEL disdrometer, the Precipitation Occurrence Sensor System on loan from the Environment Canada could be deployed at Storm Peak Lab. This device is a small X-band radar and can be used as a gauge for measuring amounts of both liquid and solid precipitation. 
A Pacific Northwest National Laboratory Basic Radiometer System will be deployed on the deck at SPL to provide downwelling shortwave and longwave radiation measurements the same as for the Thunderhead site. Additionally, Pacific Northwest National Laboratory will be supplying a sky imager equipped with a new updated Axis 211 camera with significantly improved low light capability. This will provide early morning sky images useful for daily operations decisions, as well as provide the standard fractional sky cover retrievals and visual documentation of sky conditions during the campaign.

\subsection{CAMPS}

The CAMPS project led by Dr. Linnea Avalone of the University of Colorado will focus on in situ and remote sensing measurements of wintertime clouds over the Park Range of the Rocky Mountains in northern Colorado. These clouds are generally mixed-phase; the combination of ice, liquid and water vapor presents challenges both to measurements and modeling, and consequently, to understanding their impact on atmospheric radiation and precipitation generation. CAMPS will use the Wyoming King Air instrumented with both remote (cloud radar and cloud lidar) and in situ sensors (cloud and particle probes, total water hygrometer) to gather data about the vertical and horizontal structure of cold mixed-phase clouds. Macrophysical and microphysical parameters will be analyzed with respect to cloud formation mechanisms and local topography to assess the role of variable vertical forcing. In addition, this project is timed to function in concert with STORMVEX. The measurements gathered during CAMPS flights will provide in situ data in the upper regions of clouds and will help to assess the horizontal and vertical inhomogeneities of cloud properties. CAMPS will operate roughly in the January to March 2011 timeframe. Approximately 25 flights are expected with a nominal four-hour duration of each flight.

\subsubsection{CAMPS Experiment Design}

There are two principal aspects to the science objectives of CAMPS that have defined the necessary instrumentation and platform (Wyoming King Air) for the project. The first set of objectives has to do with the processes that control the evolution of clouds and production of precipitation in complicated mixed-phase cloud systems over regions of complex terrain. The occurrence of pockets of liquid water in various regions of the storm system and the co-occurrence of ice within the storm will provide critical information on these processes. The second set of objectives is associated with improving information retrieval from remote sensing. Ground-based and space-based remote sensing has the capacity to provide a vast quantity of information regarding these cloud systems and their role in the energy and hydrological balance of storms that are an important part of the regional climate in areas of complex terrain.

However, the remote sensors are limited by the amount of independent information they can provide and the natural complexity of the storm systems due to topography and meteorology. In situ data collection coordinated with remote sensing from the ground and space will allow us to understand what assumptions are reasonable and how to best constrain uncertainty in retrievals of cloud and precipitation properties.

The Wyoming King Air is uniquely suited for the CAMPS project for a number of reasons: (1) it is based close to the study region (in Laramie, about $130 \mathrm{~km}$ away), minimizing transit time, maximizing time spent on-station, and minimizing deployment costs; (2) it is certified to fly in icing conditions, which are anticipated to occur within some of the mixed-phase clouds to be sampled; (3) it flies at relatively slow speeds, which lessens the complications of particle sampling on a moving platform; and (4) it routinely carries a well-characterized payload specifically designed for sampling clouds. 
Instrumentation for CAMPS has been selected to accomplish the objectives outlined above. We have requested a suite of particle sensors that typically flies on the King Air to measure cloud particles ranging in size from less than $1 \mu \mathrm{m}$ up to about $185 \mu \mathrm{m}$ (FSSP 100 and OAP-200X), plus particle imagers for both cloud and precipitation particles (OAP-2DC and OAP-2DP). In addition, we plan to fly a Rosemount icing sensor and DMT liquid water content probe.

We will also fly a user-supplied instrument, the closed-path laser hygrometer (CLH) from the University of Colorado to measure total condensed water (Davis et al. 2007). The original CLH was designed for cirrus cloud observations; a copy with characteristics better suited to measurement in low-altitude, wetter clouds will be built for this project. Many previous studies relied on integration of particle size distributions, which are often incomplete, to calculate ice water content (IWC). For example, Moss and Johnson (1993) derived ice-to-water ratios from images of cloud particles larger than $125 \mu \mathrm{m}$ as measured by an OAP-2DC. However, the errors in the calculation of the ice-phase water content from twodimensional particle images can be as large as a factor of two or three because of uncertainties in converting size to mass or area to mass (Korolev et al. 2003). By contrast, the CLH samples particles larger than a few microns (the actual cutoff depends on the design and location of the instrument inlet) to several hundred microns in diameter with high efficiency. The particles are evaporated, and the resulting vapor is quantified by infrared absorption, providing a measure of total condensed water. These measurements of total water will not only allow for testing of the methods used to convert particle size distributions to IWC, but will also provide a data set for more direct comparison with LWC/IWC derived from remote-sensing (e.g., lidar and radar) observations. By difference with the DMT LWC probe, this measurement will also provide an estimate of IWC within the mixed-phase clouds.

We have also requested to fly the Wyoming Cloud Radar (Pazmany et al. 1994) and Wyoming Cloud Lidar (Wang et al. 2009). Together, these remote sensors will provide a detailed picture of the sampled clouds, including spatial extent, temporal evolution, and information about particle phase either above or below the aircraft flight level. These instruments will aid in the search for liquid layers or pockets within the mixed-phase clouds and will provide an important link with remote observations made from the surface near SPL. The strength of the combination of radar and lidar observations from the King Air has recently been demonstrated in the Wyoming Airborne Integrated Cloud Observation experiment, which took place in February-March 2008 (Wang et al. 2009).

In addition to the instrumentation planned for use on the King Air specifically for CAMPS, there will be an abundance of other facilities in place for STORMVEX. AMF2 will be positioned at mid-mountain, $500 \mathrm{~m}$ below SPL on Mt. Werner. AMF2 includes a scanning W-band radar, polarization micropulse lidar, microwave radiometer, AERI, total sky imager, ceilometer, and broadband radiometers, as well as the ability to launch radiosondes (further description is available at http://www.arm.gov/sites/amf/amf2). SPL is thoroughly equipped with instrumentation for measuring the size distribution of particles (aerosol, cloud and precipitation) ranging from $3 \mathrm{~nm}$ to $6.4 \mathrm{~mm}$ in diameter (Borys and Wetzel 1997). During STORMVEX, this instrumentation will be augmented by a package from SPEC, Inc. covering particle size ranges from 1 to $3000 \mu \mathrm{m}$, plus images of particle habits.

The time period chosen for CAMPS (mid-January to mid-March) was driven by the climatology of winter storms over the Park Range; cloud events occur about every 5-7 days with durations of 1-2 days each (Borys and Wetzel 1997). In addition, orographic cloud events are common during this time of year. Based on a record of observations at SPL and from radiosonde observations made during the Inhibition of 
Snowfall by Pollution Aerosols campaigns in 2001, 2002, and 2007, it is expected that $25-33 \%$ of dates during this time period will be suitable for flight.

With the exception of one or two flights planned in coordination with overpasses of the A-Train satellites (specifically CloudSat/CALIPSO), all flights will be conducted in close coordination with the STORMVEX project. There will be several scientific, but weather-dependent foci of this experiment, which include high-level altostratus and thickening cirrus that form in advance of winter cyclones. Precipitating cloud systems associated with warm and cold frontal systems that are of a mixed convective and stratiform character will be studied, as well as unstable shallow convection that forms in the trailing regions of the cold frontal systems. Isolated orographic clouds will also be targeted when appropriate.

Aircraft measurement patterns and priorities will be designed to best meet the objectives of CAMPS, but consideration will also be given to coordination with the supporting measurements from STORMVEX towards achieving shared objectives. Thus, the aircraft flight patterns will be designed primarily to obtain two- and three-dimensional maps of cloud fields on flight days in order to capture the spatial evolution of cloud systems over complex terrain and to place the fixed ground-station measurements in a broader context.

The Wyoming King Air will have four primary flight plan styles that will be revised based on the current and projected meteorological situation. Sample flight plan drawings are given below along with a description of each generic flight plan pattern.

1. Flight Plan One will fly crosswind along the Park Range (i.e., parallel to range). Assuming a westerly wind, this will start west of Mount Werner over the Yampa Valley following a similar flight profile as Rauber and Grant (1986). The first leg will start at FL140 (flight level at 14,000 ft mean sea level based on a standard pressure), with a $2000 \mathrm{ft}$ altitude increase along the north-south flight line to a maximum altitude of FL240.

2. Flight Plan Two will start upwind of the Park Range flying downwind over Mount Werner, or planning purposes assuming a westerly wind, at FL140. At the east end of the track the King Air will climb $2000 \mathrm{ft}$ in altitude and will repeat the track heading into the wind. At the west end of the flight segment the King Air will climb an additional $2000 \mathrm{ft}$ to FL180 and will repeat the flight segment flying downwind. This upwind-downwind flight plan will be repeated until the King Air reaches FL240. With this flight plan there will be three adjacent flight lines from north to south to accommodate shifts in the winds aloft and the scanning strategy of the radars.

3. Flight Plan Three will be a CloudSat/A-train underflight that will be flown directly under either an ascending or descending satellite overpass. This flight will occur during the experiment while the Park Range is in cloud and the CloudSat overpass is within close proximity to Mount Werner $( \pm 50 \mathrm{~km})$. The NASA Langley CloudSat Orbital Prediction Tools will be used, and will be crossreferenced with the NASA Jet Propulsion Laboratory (JPL) and Colorado State University CloudSat team members.

4. Flight Plan Four will be a radar and lidar comparison flight and will likely occur in conjunction with flight plans one, two and/or three. The first goal will be to compare the data from the Wyoming Cloud Radar with that obtained by both the AMF2 scanning W-band radar (located mid-mountain) and the JPL W-band cloud radar (located at the summit). A secondary goal will be to compare the Wyoming Cloud Lidar to the AMF2 MPL. 


\subsection{STORMVEX ARM Cloud Radar Operations ${ }^{1}$}

During the STORMVEX field campaign, AMF2 will field four different cloud radars. The SWACR will be deployed at the Thunderhead Lodge site in September 2010 along with the rest of AMF2. Two new radars, X-SACR and Ka-SACR, will be deployed on the same pedestal at the AMF2 Valley Floor site. The MMCR (essentially a new radar) will be deployed in the same shelter as the X/Ka-SACR. These three radars will be installed in mid-December 2010.

Scanning strategies for SWACR and X/Ka-SACR will be identical and are set forth in Section 3.4.

\subsection{Radar Specifications}

Specifications for the SWACR, MMCR, X-SACR, and Ka-SACR are listed in Tables 7 through 10, and sight lines are shown in Figures 9 through 13.

Table 7. SWACR specifications.

\begin{tabular}{|c|c|}
\hline \multicolumn{2}{|c|}{ Specifications } \\
\hline Manufacturer & ProSensing, Inc. \\
\hline \multicolumn{2}{|r|}{ Transmitter } \\
\hline Type & $\begin{array}{l}\text { Extended Interaction Klystron Amplifier } \\
\text { (EIKA) }\end{array}$ \\
\hline Center frequency & $95.10 \mathrm{GHz}$ \\
\hline Peak power output & $1.5 \mathrm{~kW}$ \\
\hline Pulse width & $50 \mathrm{~ns}-2 \mu \mathrm{s}$ \\
\hline Polarization & Dual polarization, slant $45^{\circ}$, alternating \\
\hline Max. duty cycle & $1 \%$ \\
\hline PRF & Up to $20 \mathrm{kHz}$ \\
\hline \multicolumn{2}{|c|}{ Antenna and Pedestal } \\
\hline Type & Cassegrain (0.9 meter diameter) \\
\hline 3-dB beamwidth & $0.29^{\circ}$ \\
\hline Gain & $54.5 \mathrm{dBi}$ \\
\hline $\mathrm{X}$-pol isolation & $27 \mathrm{~dB}$ \\
\hline Azimuth scan rate & Maximum $30 \%$ sec \\
\hline Elevation scan rate & Maximum $15 \%$ sec \\
\hline \multicolumn{2}{|r|}{ Receiver } \\
\hline Type & Digital receiver \\
\hline Dynamic range & $>80 \mathrm{~dB}$ \\
\hline Noise figure & $6.0 \mathrm{~dB}$ \\
\hline Sampling rate & $120 \mathrm{MHz}$ \\
\hline Data format & $\begin{array}{l}\text { Raw: ProSensing binary } \\
\text { Ingested: NetCDF }\end{array}$ \\
\hline Data size & unknown \\
\hline
\end{tabular}

\footnotetext{
${ }^{1}$ This section contributed principally by Kevin Widener and Nitin Bharadwaj.
} 
Table 7. (Cont.)

\begin{tabular}{|l|l|}
\hline \multicolumn{2}{|l|}{ Location } \\
\hline Location & Thunderhead Lodge \\
\hline Latitude & $40.453374^{\circ} \mathrm{N}$ \\
\hline Longitude & $106.773668^{\circ} \mathrm{W}$ \\
\hline Altitude & $2760 \mathrm{~m}$ \\
\hline
\end{tabular}

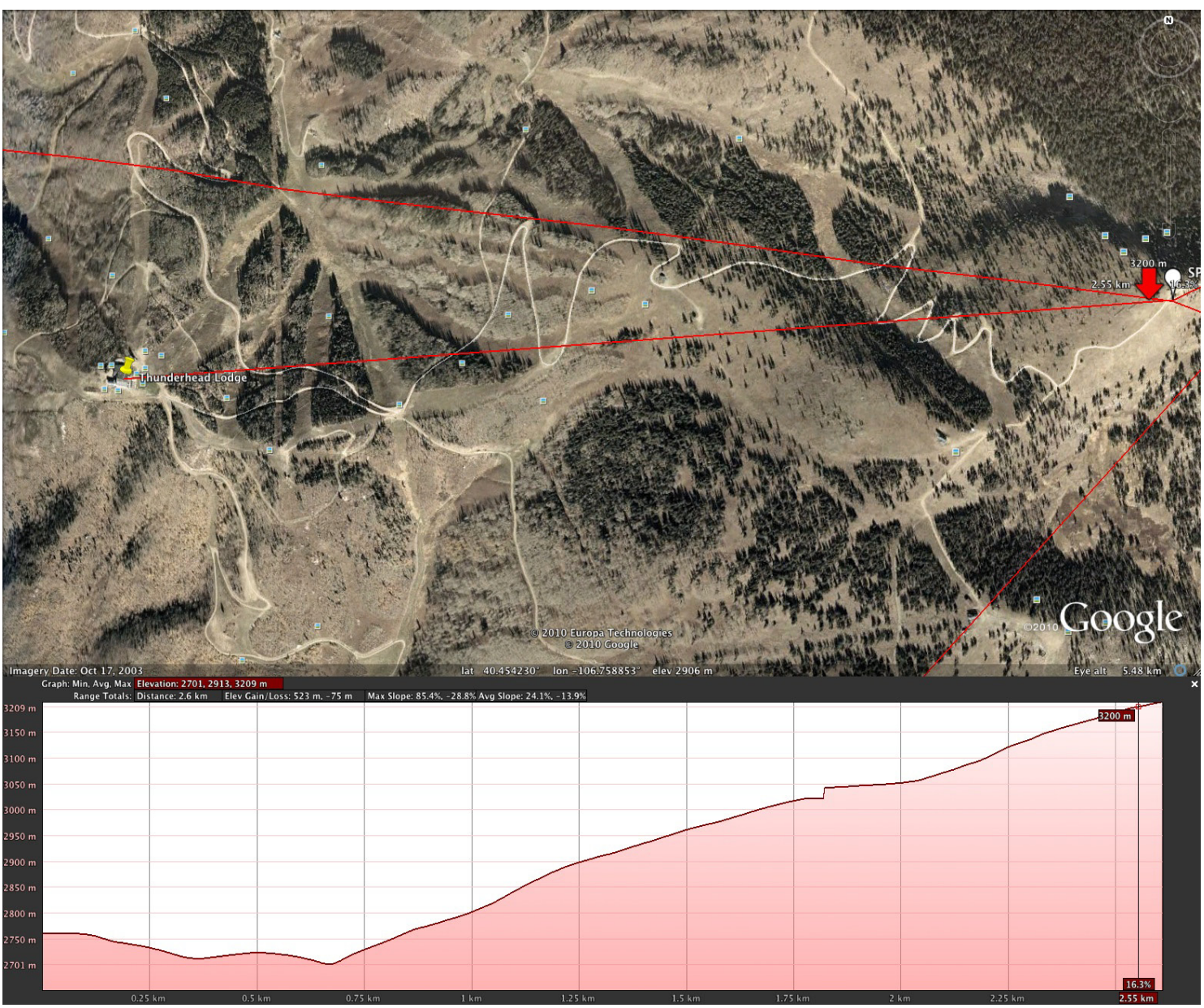

Figure 9. Thunderhead Lodge to Storm Peak Lab map and elevation profile.

Table 8. MMCR specifications.

\begin{tabular}{|l|l|}
\hline \multicolumn{2}{|c|}{ Specifications } \\
\hline Manufacturer & ProSensing, Inc. \\
\hline & Transmitter \\
\hline Type & $\begin{array}{l}\text { Traveling Wave Tube Amplifier } \\
\text { (TWTA) }\end{array}$ \\
\hline Center frequency & $34.86 \mathrm{GHz}$ \\
\hline
\end{tabular}


Table 8. (Cont.)

\begin{tabular}{|l|l|}
\hline \multicolumn{1}{|l|}{ Transmitter } \\
\hline Peak power output & $200 \mathrm{~W}$ \\
\hline Pulse width & $50 \mathrm{~ns}-2 \mu \mathrm{s}$ \\
\hline Polarization & Single polarization, zenith pointing \\
\hline Max. duty cycle & $1 \%$ \\
\hline PRF & Up to $20 \mathrm{kHz}$ \\
\hline & Antenna \\
\hline Type & Cassegrain $(0.9$ meter diameter $)$ \\
\hline 3-dB beamwidth & $0.29^{\circ}$ \\
\hline Gain & $54.5 \mathrm{dBi}$ \\
\hline X-pol isolation & $27 \mathrm{~dB}$ \\
\hline & Receiver \\
\hline Type & Digital receiver \\
\hline Dynamic range & $>80 \mathrm{~dB}$ \\
\hline Noise figure & $6.0 \mathrm{~dB}$ \\
\hline Sampling rate & $120 \mathrm{MHz}$ \\
\hline Data format & Raw: ProSensing binary \\
& Ingested: NetCDF \\
\hline Data size & unknown \\
\hline & Location \\
\hline Location & Steamboat Springs Valley Floor Site \\
\hline Latitude & $40.463680^{\circ} \mathrm{N}$ \\
\hline Longitude & $106.816165^{\circ} \mathrm{W}$ \\
\hline Altitude & $2082 \mathrm{~m}$ \\
\hline &
\end{tabular}

Table 9. X-SACR specifications.

\begin{tabular}{|l|l|}
\hline \multicolumn{2}{|l|}{ Specifications } \\
\hline Manufacturer & ProSensing, Inc. \\
\hline & Transmitter \\
\hline Type & $\begin{array}{l}\text { Traveling Wave Tube Amplifier } \\
\text { (TWTA) }\end{array}$ \\
\hline Center frequency & $9.70 \mathrm{GHz}$ \\
\hline Peak power output & $20 \mathrm{~kW}$ \\
\hline Pulse width & $100 \mathrm{~ns}-40 \mu \mathrm{s}$ \\
\hline Polarization & Dual polarization, slant $45^{\circ}$, alternating \\
\hline Max. duty cycle & $1 \%$ \\
\hline PRF & Up to $10 \mathrm{kHz}$ \\
\hline
\end{tabular}


Table 9. (Cont.)

\begin{tabular}{|l|l|}
\hline \multicolumn{2}{|c|}{ Antenna and Pedestal } \\
\hline Type & Cassegrain (1.82 meter diameter) \\
\hline 3-dB beamwidth & $1.40^{\circ}$ \\
\hline Gain & $42 \mathrm{dBi}$ \\
\hline X-pol isolation & $30 \mathrm{~dB}$ \\
\hline Azimuth scan rate & Maximum 36\% $/ \mathrm{sec}$ \\
\hline Elevation scan rate & Maximum 20\% $/ \mathrm{sec}$ \\
\hline & Receiver \\
\hline Type & Digital receiver \\
\hline Dynamic range & $>80 \mathrm{~dB}$ \\
\hline Noise figure & $4.5 \mathrm{~dB}$ \\
\hline Sampling rate & $120 \mathrm{MHz}$ \\
\hline Data format & Raw: ProSensing binary \\
& Ingested: NetCDF \\
\hline Data size & unknown \\
\hline & Location \\
\hline Location & Steamboat Springs Valley Floor Site \\
\hline Latitude & $40.463680^{\circ} \mathrm{N}$ \\
\hline Longitude & $106.816165^{\circ} \mathrm{W}$ \\
\hline Altitude & $2082 \mathrm{~m}$ \\
\hline &
\end{tabular}

Table 10. Ka-SACR specifications.

\begin{tabular}{|l|l|}
\hline \multicolumn{2}{|l|}{ Specifications } \\
\hline Manufacturer & ProSensing, Inc. \\
\hline & \multicolumn{1}{|c|}{ Transmitter } \\
\hline Type & $\begin{array}{l}\text { Extended Interaction Klystron Amplifier } \\
\text { (ElKA) }\end{array}$ \\
\hline Center frequency & $35.30 \mathrm{GHz}$ \\
\hline Peak power output & $1.7 \mathrm{~kW}$ \\
\hline Pulse width & $50 \mathrm{~ns}-13 \mu \mathrm{s}$ \\
\hline Polarization & Dual polarization, horizontal linear, alternating \\
\hline Max. duty cycle & $1 \%$ \\
\hline PRF & Up to $10 \mathrm{kHz}$ \\
\hline & Antenna and Pedestal \\
\hline Type & Cassegrain (1.82 meter diameter) \\
\hline 3-dB beamwidth & $0.33^{\circ}$ \\
\hline Gain & $53.5 \mathrm{dBi}$ \\
\hline X-pol isolation & $27 \mathrm{~dB}$ \\
\hline Azimuth scan rate & Maximum $36^{\circ} / \mathrm{sec}$ \\
\hline
\end{tabular}


Table 10. (Cont.)

\begin{tabular}{|l|l|}
\hline \multicolumn{2}{|c|}{ Antenna and Pedestal } \\
\hline Elevation scan rate & Maximum 20\% $/ \mathrm{sec}$ \\
\hline & \multicolumn{1}{|c|}{ Receiver } \\
\hline Type & Digital receiver \\
\hline Dynamic range & $>80 \mathrm{~dB}$ \\
\hline Noise figure & $6.0 \mathrm{~dB}$ \\
\hline Sampling rate & $120 \mathrm{MHz}$ \\
\hline Data format & $\begin{array}{l}\text { Raw: ProSensing binary } \\
\text { Ingested: NetCDF }\end{array}$ \\
\hline Data size & unknown \\
\hline & \multicolumn{1}{|c|}{ Location } \\
\hline Location & Steamboat Springs Valley Floor Site \\
\hline Latitude & $40.463680^{\circ} \mathrm{N}$ \\
\hline Longitude & $106.816165^{\circ} \mathrm{W}$ \\
\hline Altitude & $2082 \mathrm{~m}$ \\
\hline
\end{tabular}

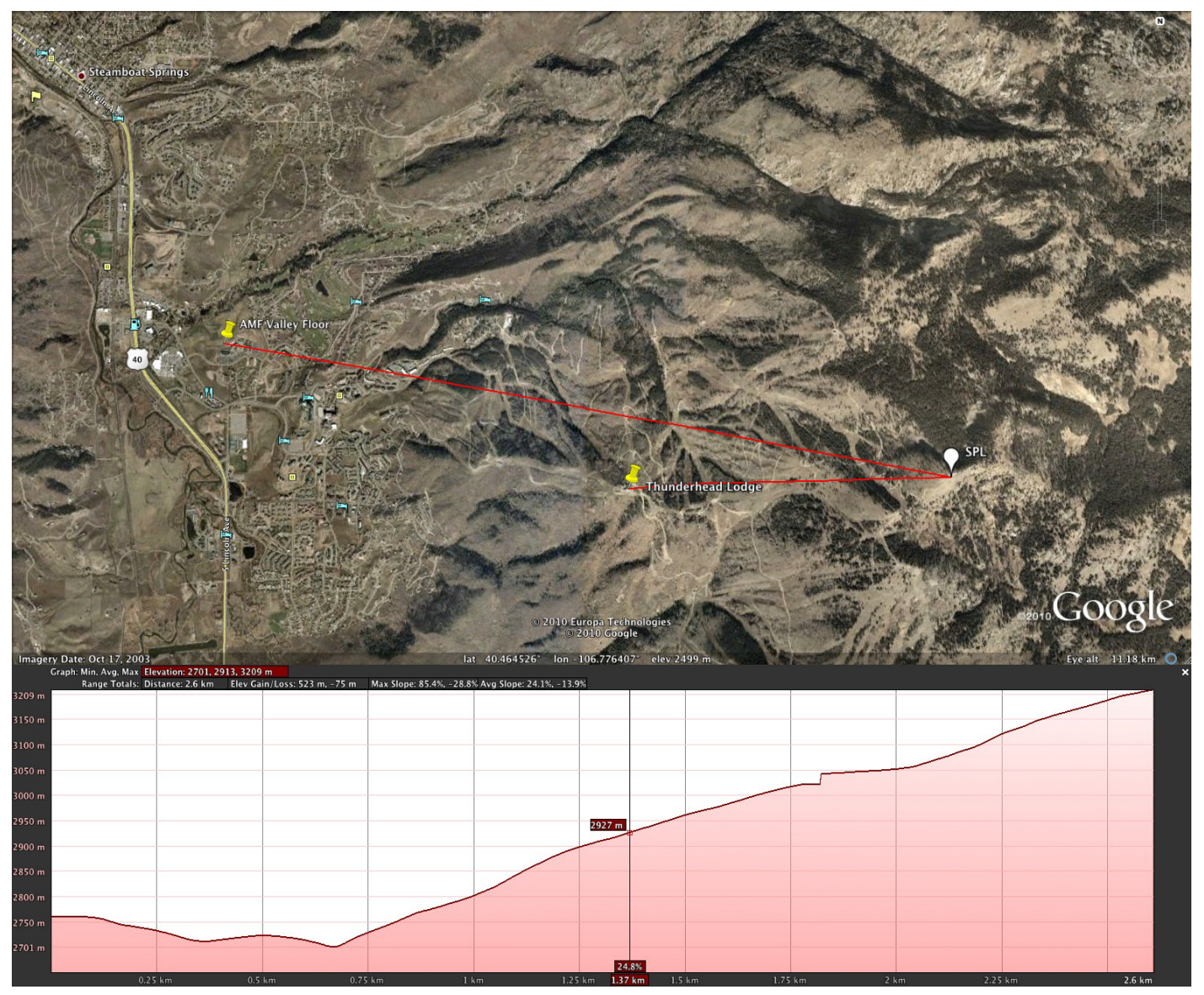

Figure 10. Map and elevation profile from Valley Floor site to SPL. 


\subsection{Calibration/Verification}

Calibration of the scanning radars (SWACR, X-SACR, and Ka-SACR) will be achieved by erecting trihedral corner reflectors of the sufficient size at an appropriate range. A crank-up tower will elevate the corner reflectors above ground clutter with a fiberglass pole on the top. The range from the radar to the corner reflector will be between 250 and 500 meters.

Calibration of the MMCR shall be verified through comparison with the calibrated Ka-SACR.

We also intend on deploying two PARSIVEL disdrometers at a to-be-determined location for precipitation retrieval verification. These disdrometers will be collocated and installed orthogonally to each other to minimize the effects of wind- blown snow.

\subsubsection{SWACR Corner Reflector}

Will be possibly located at the top of the B.C. ski lift located $440 \mathrm{~m} @ 123^{\circ}$ from the SWACR.

\subsubsection{X/Ka-SACR Corner Reflector}

Location: TBD.

\subsection{Local NEXRAD Locations}

Unfortunately, coverage NWS WSR-88D (NEXRAD) radars of the STORMVEX domain are not ideal. In addition to significant distances, there are also significant terrain features between these radars and the STORMVEX domain. Figures 11, 12, and 13 show maps and elevation profiles of the three closest WSR-88D radars. 


\subsubsection{Cheyenne, WY (KCYS Radar)}

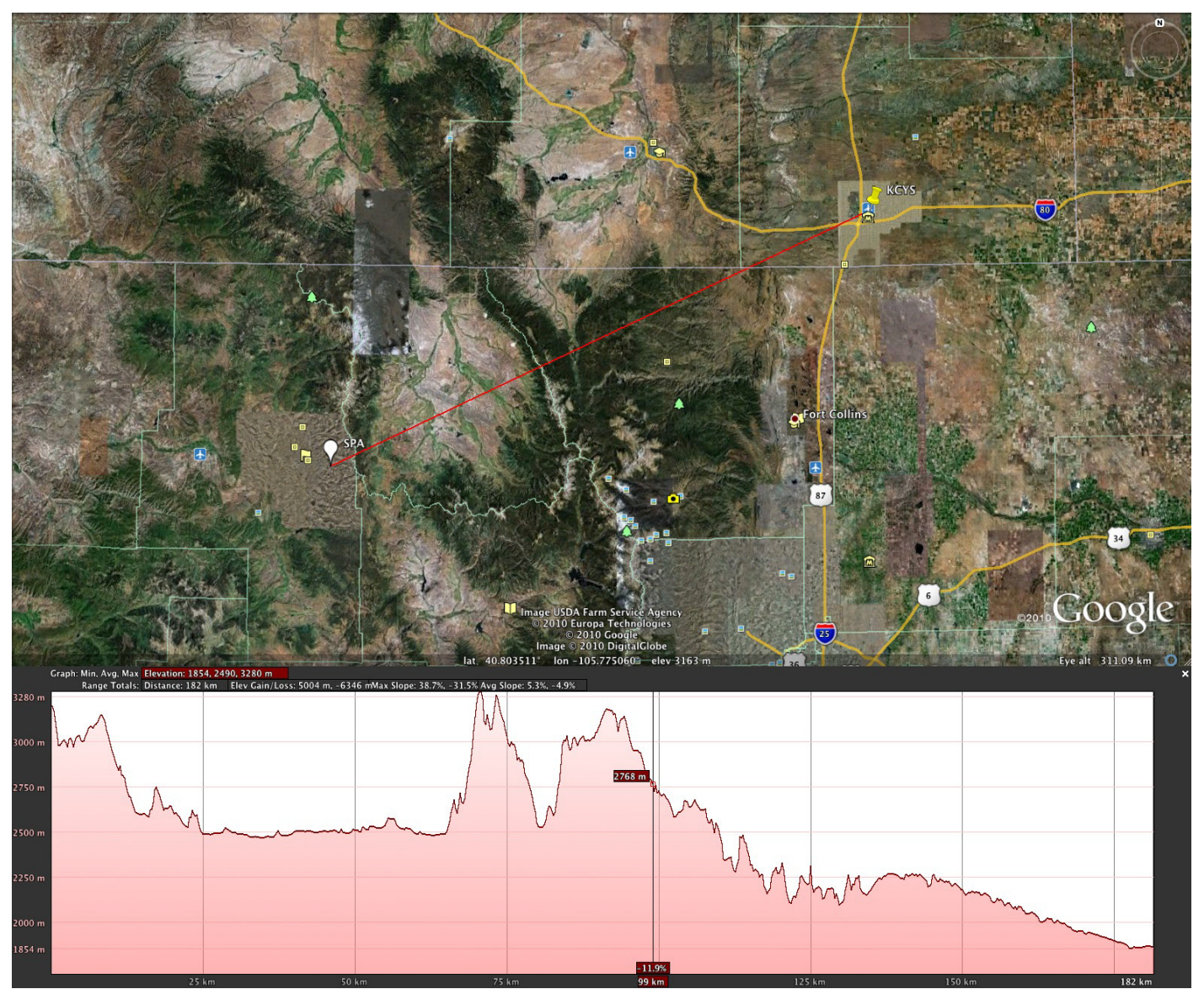

Figure 11. Map and elevation profile between Storm Peak Lab and KCYS radar. 


\subsubsection{Denver, CO (KFTG Radar)}

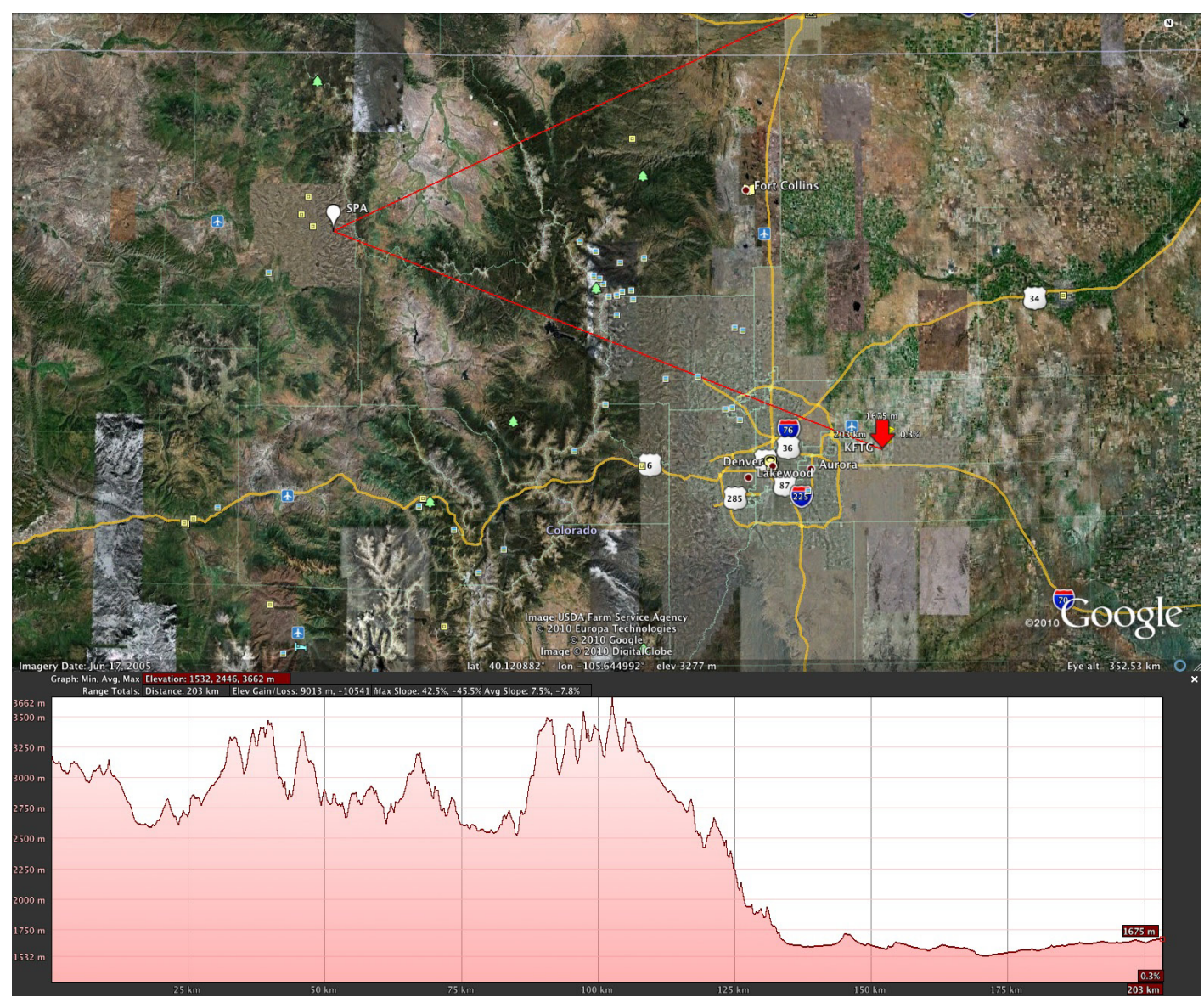

Figure 12. Map and elevation profile between KFTG radar and SPL. 


\subsubsection{Grand Junction, CO (KGJX Radar)}

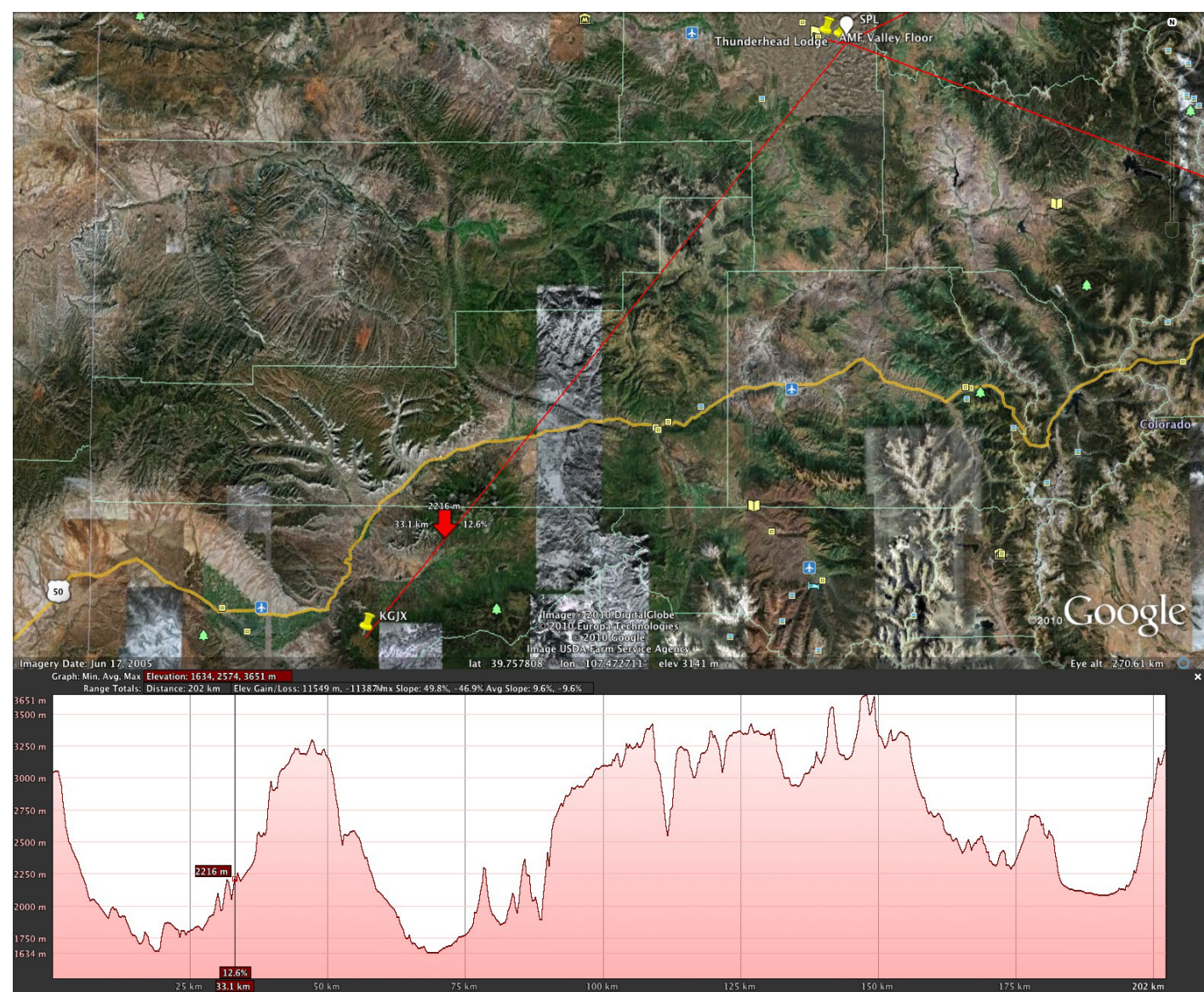

Figure 13. Map and elevation profile between KGJX radar and SPL.

\subsection{Scanning Strategies}

The SWACR, which will be deployed at the Thunderhead site, will scan in 30-min intervals. To satisfy different STORMVEX science objectives, a sequence of 11 scans/pointings will be performed during each interval. Each sequence will start at the top of the hour and $30 \mathrm{~min}$ after the hour. The different scans/pointings in the sequence and an approximate time required are listed below. The azimuth and elevation angles are also shown (az and el, correspondingly).

1. An over the top Range-Height Indicator (RHI) scan at az $=87.2^{\circ}(0.75 \mathrm{~min})$

2. An over the top RHI scan at $\mathrm{az}=60^{\circ}(0.75 \mathrm{~min})$

3. An over the top RHI scan at $\mathrm{az}=30^{\circ}(0.75 \mathrm{~min})$

4. An over the top RHI scan at $\mathrm{az}=0^{\circ}(0.75 \mathrm{~min})$

5. An over the top RHI scan at $\mathrm{az}=270^{\circ}(0.75 \mathrm{~min})$

6. An over the top RHI scan at $\mathrm{az}=240^{\circ}(0.75 \mathrm{~min})$ 
7. A $360^{\circ}$ surveillance scan at $\mathrm{el}=11^{\circ}$ or some other angle $(\sim 1.5 \mathrm{~min})$

8. A $360^{\circ}$ Velocity Azimuth Display scan at el $=75^{\circ}(\sim 0.75 \mathrm{~min})$

9. Fixed beam pointing in the SPL direction $\left(\mathrm{el}=11^{\circ}, \mathrm{az}=87.2^{\circ}\right)(\sim 5 \mathrm{~min})$

10. Fixed beam pointing in the corner reflector direction $\left(\mathrm{el}=6.25^{\circ}, \mathrm{az}=122^{\circ}\right)(\sim 0.5 \mathrm{~min})$

11. Vertical pointing $(\sim 18 \mathrm{~min})$

The purpose of the first 6 scans (so-called "domers") is to construct a volume scan to get a 3 dimensional (3D) structure of a storm/cloud, to get polarimetric information about hydrometeors, to get vertical profiles of reflectivity over the SPL site (during the first domer), and to get instantaneous vertical cross section of the event in different directions. The azimuthal direction of the first RHI scan (i.e., $87.2^{\circ}$ ) is pointing to the SPL. The purpose of the seventh scan in the scan table shown above is to get area coverage of the event. The $11^{\circ}$ elevation for this scan corresponds to the Thunderhead-SPL line of sight at $\mathrm{az}=87.2^{\circ}$. The eighth scan listed above serves a purpose of getting a vertical profile of horizontal winds. At the elevation of $75^{\circ}$, the horizontal wind velocity folding will occur at $32 \mathrm{~m} \mathrm{~s}^{-1}$ for $10 \mathrm{kHz}$ radar pulse repetition frequency. Slant beam pointing over SPL (scan 9) will provide "collocated" radar and in situ measurements at the SPL site. Fixed beam pointing in the corner reflector direction (el $=6.25^{\circ}$, $\mathrm{az}=122^{\circ}$ ) will serve calibration purposes. Vertical beam pointing is the main mode for the ARM cloud microphysical retrievals. It will take about $18 \mathrm{~min}$ (or $\sim 60 \%$ of all time). The exact timing of this pointing will be dictated by the necessity of starting a new sequence at top of the hour or 30 min after the hour.

The scan rate for the domer scans (1 through 6) and the surveillance scan (scan 7) will be $4 \%$ sec ( $\sim 10$ beams per second) with pulse repetition frequency $=10 \mathrm{kHz}, 1024$ pulses per beam including 512 pulses for co-polar returns and 512 pulses for cross-polar returns. A 32 point Fast Fourier Transform procedure will be employed with 16 spectral averages per polarization and $45 \mathrm{~m}$ gate spacing. Doppler spectra will be used for calculating Doppler moments but spectral information in the scanning modes will be not recorded. The Velocity Azimuth Display scan (\#8) will be performed with a scan rate of $8 \% \mathrm{sec}$ ( $\sim 20$ beams per second) with 512 pulses in a beam. Slant and vertical beam pointings (scan 9-11) will be performed with parameters used for the vertically pointing WACR radar (i.e., dwell tome $\sim 2 \mathrm{sec}$, 256 FFT points, 160 spectral averages).

The two-wavelength SACR will be operated from the valley floor site using the same scan strategy and timing. The only differences will be in the particular azimuth and elevation angles for scans 1, 7, 9, and 10. These angles will be chosen in such a way that they will correspond to the direction to the SPL site (for scans 1 and 9) and the corner reflector (for scan 10).

The JPL W-band radar will be collocated with SACR on the valley floor. It is requested that it also scans in 30-min intervals spending the first 12 min of each interval for RHI scans in the direction of SPL. The remaining 18 min of each scan will be spent on vertical pointing.

\subsection{Radar Quicklooks}

ProSensing, Inc is manufacturing all of the cloud radars that will be deployed during STORMVEX. ProSensing does not provide a suitable real-time display of their radar output. It will therefore be necessary for the ARM instrument mentors to develop these quicklooks for field campaign support. 
Since the AMF2 site data system ingests the raw ProSensing binary data once every hour, it is necessary to build quicklooks based on the raw ProSensing data format.

Quicklooks for MMCR will be very similar to what has been done for other field campaigns, most recently SPARTICUS at SGP.

\subsection{ARM Radar Contacts}

Kevin Widener

Phone:

509.528 .9565 (office/mobile)

Email:

kevin.widener@pnl.gov

Nitin Bharadwaj

Phone:

509.375.4267 (office)

Email:

nitin@pnl.gov 


\subsection{STORMVEX Operations}

STORMVEX is nominally scheduled to operate from 1 November 2010 until 31 March 2011. AMF2 facilities will begin integration at the various locations in the Steamboat area in mid-September 2010, with operational testing beginning in early October. Following 31 March 2011, AMF2 instrumentation will continue data collection until snow conditions allow for removal of the instrumentation from the sites. During the period after 31 March 2011, cloud probes at SPL will be maintained only on a routine basis as SPL personnel are available.

Each of the primary facilities during STORMVEX will have a unique set of operational modes based on the complexity and capabilities of the individual facilities and their operators. The standard working days and times for operations support personnel will be Monday through Saturday for 10 hours per day. Typical hours will be 8:00 a.m. to 6:00 p.m., although these time windows may be pushed forward by up to an hour or backward by up to 2 hours depending upon the conditions. Sunday will be considered a hard down day. Modifications to this basic schedule are possible, and likely, at opportune times identified by the site scientist and will require coordination with the relevant personnel as far in advance as possible. It is a priority to maintain regular down days so that site personnel have sufficient time for personal activities. Thus, any modified schedules will include consideration of down time.

\subsection{Site Usage}

DRI - Storm Peak Laboratory maintains a United States Forest Service (USFS) special use permit for conducting atmospheric science in the Routt National Forest. All atmospheric science research conducted within the area managed at Steamboat Ski Area is conducted with the permission of the Steamboat Ski and Resort Corporation (SSRC). DRI - Storm Peak Laboratory has a unique relationship with SSRC that allows for the operations of Storm Peak Lab. All STORMVEX participants should please respect the preexisting relationship that DRI - Storm Peak Laboratory has with SSRC and the USFS. As the STORMVEX research project will be conducted on Federal Lands managed by SSRC, it is with their cooperation that we are able to achieve the science goals of STORMVEX.

\subsection{Personnel Responsibilities}

- ARM site operators (2-3 people typically from Argonne National Laboratory, with periodic Brookhaven National Laboratory staff) will be responsible for all operations at the Valley Floor, Christie Peak, and Thunderhead locations. They operate/maintain the core ARM Facility AMF/MAOS instruments during standard working hours and are expected to leave the instruments in their standard operation modes when outside of standard working hours. Volunteers may assist the ARM site operators with daily radiosonde launches. From time to time, additional personnel associated with the Department of Energy may be on site and will either conduct individual work or coordinate with the site operators. These operators are expected to communicate the status of all instruments to the site scientist each day by 9 am. Argonne National Laboratory will be responsible for scheduling the ARM site operators.

- SPL operators (Ian, Gannet, associates) are responsible for operating and maintaining the SPL cloud probes and precipitation gauges during standard working hours. On days when a SPL operator did not sleep at the SPL, the start time may be delayed to 8:30-9:30 depending on the mode and 
availability of transportation to the SPL. The SPL operators can assist with the SPEC cloud probes as possible, but are not ultimately responsible for their operation. Since SPL operations require time for personnel to reach SPL, prepare, and operate the instruments $(\sim 2 \mathrm{hr})$, it is preferable for operations outside of standard hours to be established one day ahead of time if possible, or be subject to possible delays. The SPL operators will communicate the status of all instruments to the site scientist each day by 9 am.

- Graduate students associated with the STORMVEX science team and/or SPEC personnel are responsible for operating and maintaining the SPEC cloud probes at the SPL during standard working hours. These people will also play a support role for operating the SPL cloud probes, specifically including rime removal, and maintaining the ancillary instruments (i.e., precipitation gauges, radiometers, etc.). The students will communicate the status of SPEC and ancillary instruments to the site scientist each day by $9 \mathrm{am}$. At least one graduate student will be supplied by the University of Utah for the time period of 1 November through early January. From early January through the end of March, graduate students from the University of Washington will be on site.

- Site scientists (STORMVEX science team members Mace, Marchand, or Shupe) will be responsible for scientific oversight, communicating with the appropriate science and operation team members who are not on site, evaluating the quality of operations, obtaining forecast information, deciding upon and coordinating non-standard operational modes or operations outside of standard work hours, and communicating with collaborating project personnel. On a daily basis, the current site scientist will obtain instrument status updates from each instrument site and ensure that status information is updated and documented on a wiki website. The site scientist will hold teleconference calls with representatives from the National Science Foundation CAMPS project in order to most effectively coordinate their aircraft operations with the STORMVEX operations. For example, STORMVEX equipment should be in full, attended, observational mode when the CAMPS aircraft is flying. A preliminary schedule for the site scientists is included in Table 11.

- Weather forecasting will be provided by the local Weather Service office. Mike Meyers will provide a local weather forecast via email at about 5 am each day. Further forecast email updates may be available throughout the day.

Table 11. STORMVEX science team on-site personnel.

\begin{tabular}{|l|l|l|}
\hline \multicolumn{1}{|c|}{ Role } & \multicolumn{1}{c|}{ Name } & \multicolumn{1}{c|}{ Dates } \\
\hline Site scientist & Jay Mace & 1 November-28 November \\
\hline Site scientist & Matthew Shupe & 29 November-19 December \\
\hline Site scientist & Roger Marchand & 19 December-9 January \\
\hline Site scientist & Jay Mace & 10 January-30 January \\
\hline Site scientist & Matthew Shupe & 31 January-27 February \\
\hline Site scientist & Roger Marchand & 28 February-28 March \\
\hline Graduate student & UU & TBD \\
\hline Graduate student & UU & TBD \\
\hline Graduate student & UW \#1 & early January-TBD \\
\hline Graduate student & UW \#2 & TBD-end March \\
\hline
\end{tabular}




\subsection{Standard Operations}

\subsubsection{Valley Floor Site}

There will be twice daily radiosondes with launches at 8:00 a.m. and 3:00 p.m. local time. These radiosoundings require the operator(s) to be on site approximately one hour prior to launch time. All other instruments will be in operation 24 hours per day, 7 days per week. Regular maintenance will occur during standard working hours.

\subsubsection{Christie Peak Site}

All instruments will be in operation 24 hours per day, 7 days per week. Regular maintenance (filter changes, snow removal, inspection, etc.) will occur during standard working hours.

\subsubsection{Thunderhead Site}

All instruments will be in operation 24 hours per day, 7 days per week. Most instruments are fixed into a single operational mode. The MWR will be operated in a consistent schedule of vertically pointing with tip calibrations every hour. The SWACR will be operated using a single scan-table that includes a variety of scanning strategies (see Section 3.4).

\subsection{Conditional Operations}

\subsubsection{Valley Floor Site}

Under clear sky conditions, the wind profiler will operate in 3D-wind mode. Under cloudy skies, the wind profiler will operate in vertically pointing $1 \mathrm{D}$, or "precipitation" mode. On occasion, when requested by the site scientist, additional radiosonde launches may occur. These special events will be planned in advance to ensure the availability of necessary operators. No other conditional operations are planned for this site.

\subsubsection{Christie Peak Site}

No conditional operations are planned for this site.

\subsubsection{Thunderhead Site}

Under special conditions, or if the need arises during standard operations, SWACR scan tables can be modified to accommodate new/adjusted scientific objectives. 


\subsubsection{Storm Peak Lab}

During standard working hours, the cloud probes will be in operation when clouds are present at SPL. SPEC cloud probes are nominally on the same schedule as SPL cloud probes. Cloud probes will typically not be in operation outside of standard working hours unless specifically requested and coordinated by the site scientist.

\subsection{Communications and Interaction Between STORMVEX and CAMPS}

There will be a close collaboration between Linnea Avalone (principal investigator of CAMPS), the University of Wyoming King Air representative, and the STORMVEX site scientist to plan CAMPS flights. This will include morning conference calls to make go/no-go decisions for the current day and afternoon discussion via email or teleconference to make plans for the next day. The afternoon call will need to take place in sufficient time for the STORMVEX site scientist to notify and perhaps stage personnel as necessary for a flight the following day.

\subsection{Operational Safety Considerations}

\subsubsection{Personal Gear and Equipment}

All participants in STORMVEX are expected to have the proper clothing for working at a high elevation with extreme weather events. Here is a standard list of equipment expectations: snow boots, thermal (i.e., wool) socks, wind- and water-proof insulated jacket, wind- and water-proof insulated snow pants, sweater (wool or other insulating material such as fleece), warm hat, neck covering, face mask, very warm gloves, ski goggles and/or good sunglasses, thermal underwear top and bottom (not cotton), sunscreen, and a water bottle.

\subsubsection{On-Mountain Activities}

When skiing or snowboarding, access to the AMF2 sites (Christy Peak, Thunderhead and Storm Peak Laboratory) is during normal ski area operations hours (8:30 a.m. to 4:00 p.m.). When skiing or snowboarding, participants are expected to follow all rules and regulations of the ski area, the National ski area responsibility code, and the Colorado skier responsibility act, listed below:

- Always stay in control and be able to stop or avoid objects.

- People ahead of you have the right of way. It is your responsibility to avoid them.

- Do not stop where you obstruct the trail or are not visible from above.

- Whenever starting downhill or merging into a trail, yield to others.

- Always use devices to help prevent runaway equipment.

- Observe all posted signs and warnings. 
- Keep off closed trails and out of closed areas.

- Prior to using any lift, you must know how to load, ride, and unload safely.

STORMVEX participants are expected to ski in-bounds (i.e., do not cross ropes, unless specifically discussed with ski patrol), and if they are planning to ski down the mountain from the laboratory, they must do so before ski patrol sweeps the mountain (approximately 4:00 pm each day). Finally, all participants in STORMVEX should be aware of the Colorado Ski Act:

Warning: Under Colorado law, a skier assumes the risk of any injury to person or property resulting from any of the inherent dangers and risks of skiing and may not recover from any ski area operator for any injury resulting from any of the inherent dangers and risks of skiing including: changing weather conditions; existing and changing snow conditions; bare spots; rocks; stumps; trees; collision with natural objects, man- made objects or other skiers; variations in the terrain; and the failure of the skiers to ski within their own abilities.

Access to sites after ski area operation hours (and pre/post season) requires either a snowmobile or snowtrack vehicle (i.e., snow cat). This method of transportation is only for selected AMF2 or Storm Peak Laboratory staff that receive proper snowmobile training and are approved by SSRC. When accessing the mountain after hours, the buddy system should always be maintained. If not traveling with a second person, a received phone call to a science team member or AMF2 staff member is required before leaving the base area, upon arrival at the facility, and upon return trip down.

\subsubsection{High Altitude IIIness Prevention}

Following these guidelines from the Colorado Altitude Research Institute can minimize high altitude illness:

- Exercise in moderation.

- Drink more water than usual. When you combine altitude with physical exertion, you need to drink before you get thirsty.

- Eat food high in carbohydrates, such as grains, pasta, fruits, and vegetables, and avoid salty foods.

- Limit alcohol consumption.

- Be sun savvy. Ultraviolet rays are more powerful at higher elevations. You will need goggles and/or sunglasses that have UV protection, at least 15 SPF, and apply several times a day. Look for broadspectrum sunscreen that blocks both UVA and UVB rays. 


\subsection{STORMVEX Data Policy}

The ARM archive will serve as the data repository of all data collected as part of the STORMVEX campaign. All participants in STORMVEX agree to adhere to the Data Sharing and Distribution Policy which can be viewed at http://www.arm.gov/data/docs/policy. In essence, this policy adheres to the concept of free and open access to all data collected during the campaign. Data collected by AMF2 instruments will be made publicly available according to policies and procedures already established. PIrelated data sets will be proprietary for a period of time (usually 6 months to 1 year) following the campaign. Subsequent to this period, all data will be freely and publicly available within the ARM archive.

CAMPS data access will follow the policies and procedures established for field campaigns by the National Science Foundation. 


\subsection{Public Outreach Plan ${ }^{2}$}

The outreach plan for STORMVEX will fulfill two major requirements; to inform the public about the goals and objectives of STORMVEX and to provide interpretive education on USFS land. These requirements are in line with the Steamboat Ski and Resort Cooperation permit with the USFS. These two goals will be accomplished via the following:

\subsection{Signage}

Signs will be erected near each of the deployment locations, as well inside Thunderhead Lodge (see Figure 14). Sign content will describe the science, the instrumentation, and how the campaign is contributing to climate change research. Construction of posts and frames for the outdoor signs is expected to take place at the same time as AMF infrastructure installation (footings, etc.) during the summer of 2010. They will be no higher than 8 feet, and placed such that AMF operations personnel have ample room to maneuver. Costs for these installations will be shared between Steamboat Springs Ski Resort and ARM. Actual signs will be added in the fall, after the AMF instrumentation arrives and installations are underway.

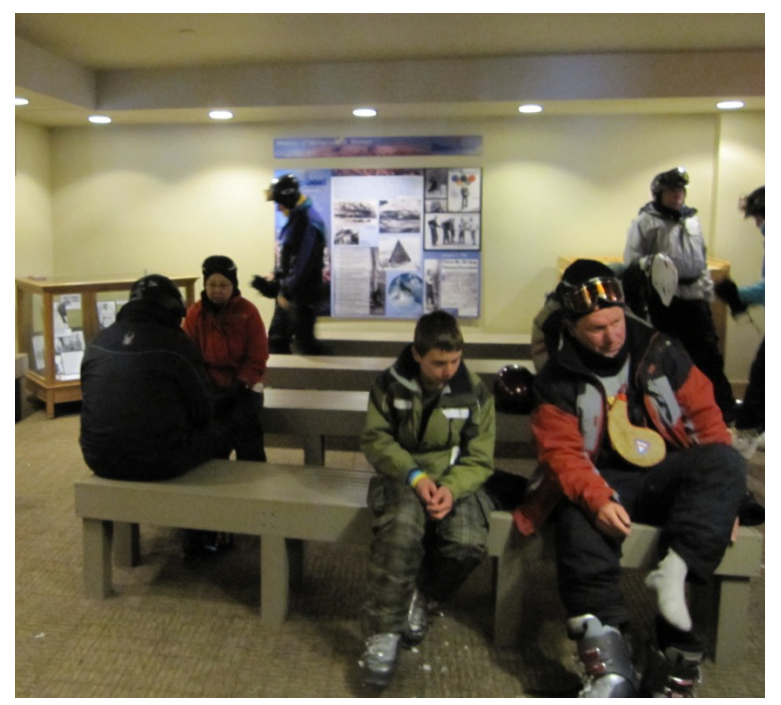

Figure 14. An interior picture of Thunderhead Lodge.

\subsection{Website}

A webpage is already online for STORMVEX (http://www.arm.gov/sites/amf/sbs/) and will be updated with additional information as appropriate throughout the campaign. Website content will be supplemented with social media tools (Facebook, Twitter).

\footnotetext{
${ }^{2}$ This section contributed principally by Lynne Roeder.
} 


\subsection{Fliers}

A "backgrounder" about the campaign will be developed as a tri-fold handout to support inquires by the public. Handouts will be available at the Ski Resort's information office and through "ambassadors" at the main gondola.

\subsection{Publicity}

In addition to occasional news articles on the STORMVEX website, an onsite media event is anticipated in the late November timeframe. This will be supported by a press release and media advisory. Potential activities include a guided tour of the instruments/facilities in town and on the mountain, followed or preceded by a media roundtable. A press conference at the AGU meeting in December is also a possibility, as well as participation at the Steamboat Weather Summit in January 2011, if it takes place. 


\subsection{References}

Ackerman, TP, AD Del Genio, RG Ellingson, RA Ferrare, SA Klein, GM McFarquhar, PJ Lamb, CN Long, and J Verlinde. 2004. Atmospheric Radiation Measurement Program Science Plan. U. S. Department of Energy. DOE/ER-ARM-0402.

Borys, RD, DH Lowenthal, SA Cohn, and WOJ Brown. 2003. "Mountaintop and radar measurements of anthropogenic aerosol effects on snow growth and snowfall rate." Journal of Geophysical Research 30(10): 1538, doi:10.1029/2002GL016855.

Borys, RD, DH Lowenthal, and DL Mitchell. 2000. "The relationships among cloud microphysics, chemistry and precipitation rate in cold mountain clouds." Atmospheric Environment 34: 2593-2602.

Borys, RD and MA Wetzel. 1997. "Storm Peak Laboratory: A research, teaching and service facility for the atmospheric sciences." Bulletin of the American Meteorological Society 78: 2115-2123.

Davis, SM, AG Hallar, LM Avallone, and W Engblom. 2007. "Measurements of ice water content with a tunable diode laser hygrometer: Calibration procedure and inlet analysis." Journal of Atmospheric and Oceanic Technology 24: 463, doi:10.1175/JTECH1975.1.

Dong, X, and GG Mace. 2003. "Profiles of low-level stratus cloud microphysics deduced from groundbased measurements." Journal of Atmospheric and Oceanic Technology 20: 45-53, 2003.

Frisch, S, MD Shupe, I Djalalova, G Feingold, and M Poellot. 2002. "The retrieval of stratus cloud droplet effective radius with cloud radars." Journal of Atmospheric and Oceanic Technology 19: 835842.

Hindman, EE. 2001. "The cloud catchers.” Weatherwise 54: 30-36.

Hindman, EE, MA Campbell, and RD Borys. 1994. "A ten-winter record of cloud-droplet physical and chemical properties at a mountaintop site in Colorado." Journal of Applied Meteorology 33: 797-807.

Korolev, AV, GA Isaac, SG Cober, JW Strapp, and J Hallett. 2004. "Microphysical characterization of mixed-phase clouds." Quarterly Journal of the Royal Meteorological Society 129: 39, doi: 10.1256/qj.01.204, 2003.

Lowenthal, DH, RD Borys, and MA Wetzel. 2002. "Aerosol distributions and cloud interactions at a mountaintop laboratory." Journal of Geophysical Research 107(D18): 4345, doi:10.1029/2001JD002046.

Mace, GG, S Benson, and S Kato. 2006b. "Cloud radiative forcing at the ARM Climate Research Facility: part 2. The vertical redistribution of radiant energy by clouds." Journal of Geophysical Research 111: D11S91, doi:10.1029/2005JD005922.

Matrosov, SY, PT May, and MD Shupe. 2006. "Rainfall profiling using Atmospheric Radiation Measurement Program vertically pointing 8-mm wavelength radars." Journal of Atmospheric and Oceanic Technology 23: 1478-1491. 
Matrosov, SY, MD Shupe, AJ Heymsfield, and P Zuidema. 2003. "Ice cloud optical thickness and extinction estimates from radar measurements." Journal of Applied Meteorology 42: 1584-1597.

Moss, SJ, and DW Johnson. 1993. "Aircraft measurements to validate and improve numerical model parameterizations of ice to water ratios in cloud." Atmospheric Research 34: 1.

Pazmany, A, R McIntosh, R Kelly, and G Vali. 1994. "An airborne $95 \mathrm{GHz}$ dual polarized radar for cloud studies." IEEE Transactions on Geoscience and Remote Sensing 32: 731-739.

Rauber, RM, and LO Grant. 1986. "Characteristics and distribution of cloud water over the mountains of northern Colorado during winter storms, Pt. 2, Spatial distribution and microphysical properties." Journal of Climate and Applied Meteorology 4: 489-504.

Shupe, MD. 2007. “A ground-based multisensory cloud phase classifier." Geophysical Research Letters 34: doi: 10.1029/2007GL031008.

Shupe, MD, T Uttal, and SY Matrosov. 2005. "Arctic cloud microphysics retrievals from surface-based remote sensors at SHEBA." Journal of Applied Meteorology 44: 1544-1562.

Turner, DD. 2005. "Arctic mixed-phase cloud properties from AERI lidar observations: algorithm and results from SHEBA." Journal of Applied Meteorology 44: 427-444.

U.S. Department of Energy. 1991. Identification, Recommendation, and Justification of Potential Locales for ARM Sites. U. S. Department of Energy, Washington, D.C. DOE/ER -0494T.

Wang, Z, P Wechsler, W Kuestner, J French, A Rodi, B Glover, M Burkhart, and D Lukens. 2009. "Wyoming cloud lidar: instrument description and applications." Optics Express 17: 13576. 


\section{Appendix A}

\section{Additional Tables}




\section{Appendix A}

\section{Additional Tables}

Table A.1. Participating organizations and PIs.

\begin{tabular}{|c|c|c|c|c|c|}
\hline $\begin{array}{l}\text { Participant/ } \\
\text { Contact PI }\end{array}$ & Location & Instruments & $\begin{array}{c}\text { Number of } \\
\text { Operators } \\
\text { Needed on } \\
\text { Site }\end{array}$ & $\begin{array}{l}\text { Funding } \\
\text { Agency }\end{array}$ & Notes \\
\hline $\begin{array}{l}\text { ARM AMF2/ } \\
\text { Brad Orr and } \\
\text { Rich Coulter }\end{array}$ & Valley Floor & Various (Table 4) & 1 & DOE & \\
\hline $\begin{array}{l}\text { ARM AMF2/ } \\
\text { Arthur Sedlacek }\end{array}$ & Christie Peak & Various (Table 3) & 1 & DOE & $\begin{array}{l}\text { Additional } \\
\text { responsibility } \\
\text { includes } \\
\text { operation of SP2 }\end{array}$ \\
\hline $\begin{array}{l}\text { Dan Cziczco, } \\
\text { PNNL }\end{array}$ & Storm Peak Lab & $\begin{array}{l}\text { Ice Nucleation } \\
\text { Chamber, } \\
\text { PALMS and AMS }\end{array}$ & 3 & DOE & $\begin{array}{l}\text { Instrument will be } \\
\text { operated during } \\
2 \text { week IOPs } \\
\text { ( } 6 \text { IOPs } \\
\text { expected) }\end{array}$ \\
\hline $\begin{array}{l}\text { Chuck Long, } \\
\text { PNNL }\end{array}$ & $\begin{array}{l}\text { Various Sites on } \\
\text { Mountain }\end{array}$ & Radiometers, TSI & 0 & DOE & $\begin{array}{l}\text { Instruments will } \\
\text { be attended by } \\
\text { DOE personnel }\end{array}$ \\
\hline $\begin{array}{l}\text { Paola Massoli, } \\
\text { Aerodyne }\end{array}$ & & $\begin{array}{l}\text { Aerosol } \\
\text { Extinction }\end{array}$ & 1 & DOE & $\begin{array}{l}\text { Instrument will } \\
\text { not require daily } \\
\text { maintenance }\end{array}$ \\
\hline $\begin{array}{l}\text { Paul Lawson, } \\
\text { SPEC Inc. }\end{array}$ & Storm Peak Lab & CPI, 2DS & 1 & $\begin{array}{l}\text { NASA } \\
\text { JPL }\end{array}$ & \\
\hline Steve Dinardo & $\begin{array}{l}\text { Storm Peak Lab } \\
\text { or Valley Floor }\end{array}$ & $\begin{array}{l}94 \mathrm{GHz} \text { Cloud } \\
\text { Radar }\end{array}$ & 1 & $\begin{array}{l}\text { NASA } \\
\text { JPL }\end{array}$ & \\
\hline $\begin{array}{l}\text { Linnea Avallone, } \\
\text { CU }\end{array}$ & Storm Peak Lab & $\mathrm{CLH}$ & 1 & NSF & $\begin{array}{l}\text { Will be attended } \\
\text { by lan McCubbin } \\
\text { during campaign }\end{array}$ \\
\hline $\begin{array}{l}\text { Linnea Avallone, } \\
\text { CU }\end{array}$ & $\begin{array}{l}\text { Laramie, } \\
\text { Wyoming }\end{array}$ & King Air, aircraft & $\mathrm{n} / \mathrm{a}$ & NSF & $\begin{array}{l}\text { CAMPS airborne } \\
\text { campaign }\end{array}$ \\
\hline
\end{tabular}


Table A.2. Participant contact information.

\begin{tabular}{|c|c|c|c|}
\hline Name, Institution & Role & Email & Phone numbers \\
\hline $\begin{array}{l}\text { Jay Mace, } \\
\text { University of Utah }\end{array}$ & Science Team & Jay.mace@utah.edu & $\begin{array}{l}\text { Office: } 801-585-9489 \\
\text { Cell: } 801-201-7944\end{array}$ \\
\hline $\begin{array}{l}\text { Sergey Matrosov, } \\
\text { CIRES/CU }\end{array}$ & Science Team & Sergey.matrosov@noaa.gov & Office: $303-497-6393$ \\
\hline Matt Shupe, CU & Science Team & matthew.shupe@noaa.gov & Office: $303-497-6471$ \\
\hline Roger Marchand, UW & Science Team & rojmarch@u.washington.edu & Office: $206-685-3757$ \\
\hline Gannet Hallar, DRI & $\begin{array}{l}\text { Science Team and } \\
\text { SPL director }\end{array}$ & gannet.hallar@dri.edu & Office: $970-819-0968$ \\
\hline Ian McCubbin, DRI & $\begin{array}{l}\text { Science Team and } \\
\text { SPL Management }\end{array}$ & mccubbin@dri.edu & Office: $970-819-2842$ \\
\hline Brad Orr, ANL & $\begin{array}{l}\text { AMF2 } \\
\text { Management }\end{array}$ & brad.orr@anl.gov & Office: $630-252-8665$ \\
\hline Rich Coulter, ANL & $\begin{array}{l}\text { AMF2 } \\
\text { Management }\end{array}$ & rlcoulter@anl.gov & Office: $630-252-5833$ \\
\hline Linnea Avallone, CU & CAMPS & Linnea.Avallone@colorado.edu & Office: $303-492-5913$ \\
\hline Chuck Long, PNNL & Radiometers & chuck.long@pnl.gov & Office: $509-372-4917$ \\
\hline Arthur Sedlacek & AOS & sedlacek@bnl.gov & Office: $631-344-2404$ \\
\hline Dan Cziczco, PNNL & Ice Nucleation & daniel.cziczo@pnl.gov & Office: $509-375-2725$ \\
\hline Paul Lawson, SPEC & Microphysics & plawson@specinc.com & Office: $303-449-1105$ \\
\hline Kevin Widener & ARM Radar & kevin.widener@pnl.gov & Office: $509-528-9565$ \\
\hline Nitin Bharadwaj & ARM Radar & nitin@pnl.gov & Office: $509-375-4267$ \\
\hline
\end{tabular}




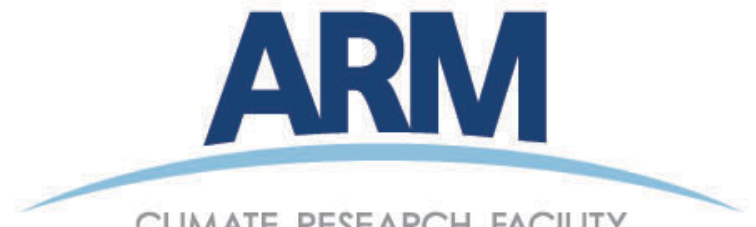

CLIMATE RESEARCH FACILITY

www.arm.gov

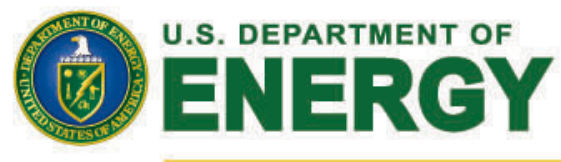

Office of Science 